\title{
DISSERTATION
}

\section{EXPERIENCES OF STUDENTS WITH VISUAL IMPAIRMENTS IN ADOPTION OF DIGITAL TALKING TEXTBOOKS: AN INTERPRETATIVE PHENOMENOLOGICAL ANALYSIS}

Submitted by

Ahamad Hussin

School of Education

\author{
In partial fulfillment of the requirements \\ For the Degree of Doctor of Philosophy \\ Colorado State University \\ Fort Collins, Colorado
}

Summer 2013

Doctoral Committee:

Advisor: James E. Folkestad

Carole J. Makela

William M. Timpson

Thomas E. Johnson 
Copyright by Ahamad Hussin 2013

All Right Reserved 


\begin{abstract}
EXPERIENCES OF STUDENTS WITH VISUAL IMPAIRMENTS IN ADOPTION OF

DIGITAL TALKING TEXTBOOKS: AN INTERPRETATIVE PHENOMENOLOGICAL
\end{abstract}

\begin{abstract}
ANALYSIS
ANALYSIS

Assistive technology devices have become essential tools for students with visual impairments. In 2009, the Malaysian Ministry of Education introduced Digital Talking Textbooks (DTTs) for selected subjects to facilitate learning. The purpose of this qualitative study was to explore, describe, and interpret the experiences of students with visual impairments in using DTTs to assist their learning. The study looked at what factors influence students with visual impairments to adopt or to reject DTTs. Data were obtained from 12 students' in-depth interviews. Tentative themes emerged, were refined, and became the six emergent superordinate themes for this research: (1) functionality of the innovation, (2) support to use the innovation, (3) knowledge of the innovation, (4) challenges for effective use of the innovation, (5) alternatives to the innovation, and (6) adaptation of the innovation. Providing in-house training for teachers and students, affordable tools, and sufficient trial and usage time for students are recommended to ensure DTTs are efficiently adopted.
\end{abstract}




\section{ACKNOWLEDGMENTS}

This doctorate process and research fulfills one of my lifetime goals. It is truly an amazing experience to have reached this point of such a challenging journey and I am forever grateful to these significant individuals who have accompanied me throughout this journey. I want to say thank you to:

- My outstanding advisor and committee members for their contributions of experience, knowledge, and continuous encouragement: My advisor, Dr. James E. Folkestad; my methodologist, Dr. Carole J. Makela; and my other committee members, Dr. William M. Timpson and Dr. Thomas E. Johnson.

- The Ministry of Education, Malaysia: For awarding me a doctorate scholarship to pursue this study.

- The school administrators and teachers at SMPK (Bermasalah Penglihatan): For their cooperation in providing access to the participants of this dissertation study.

- My family in Malaysia: Ayahsu and Ciksu; Abah and Umi; and all my beloved siblings, nephews, and nieces. Thank you for the support and prayers.

- My family in Laramie, Wyoming, USA: My beloved sister Noor Syamilah Zakaria, my brother Azmanhazim Abdul Aziz, and my sweethearts Adam Azmanhazim and Dina Azmanhazim. Each of you has accented my life personally and professionally, leaving me wordless to describe my affection for all of you.

- To my beautiful wife, Rusmin Yunus: Thank you for being you. I love you always. 


\section{DEDICATION}

This doctorate dissertation study is dedicated to all of the students with visual impairments who have shared their perspective and educated me in many ways.

May this study enlighten others as well. 


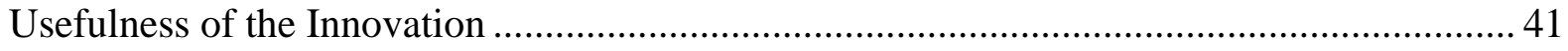

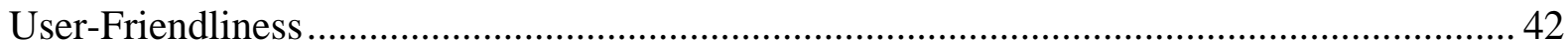

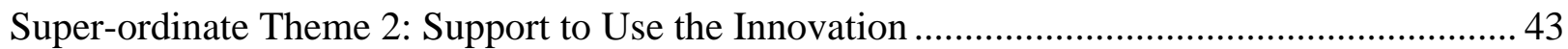

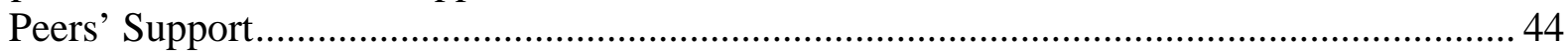

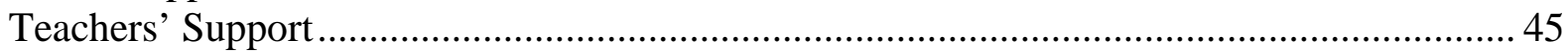

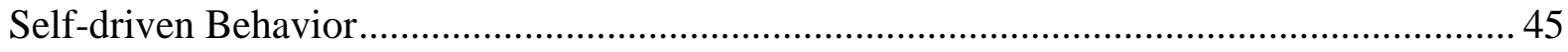

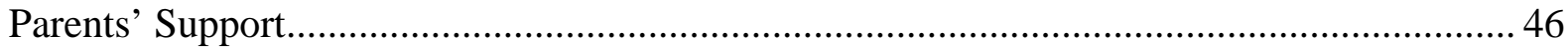

Super-ordinate Theme 3: Knowledge of the Innovation ......................................................... 46

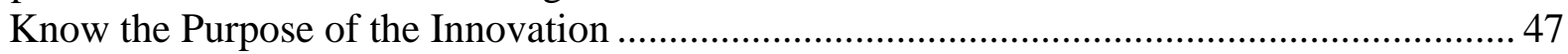

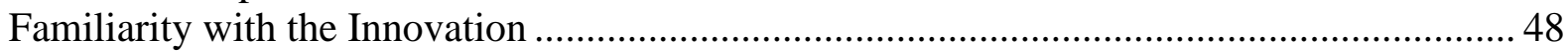

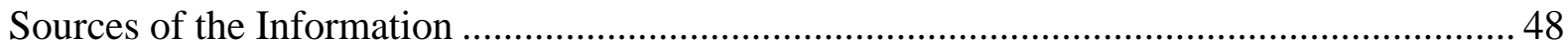

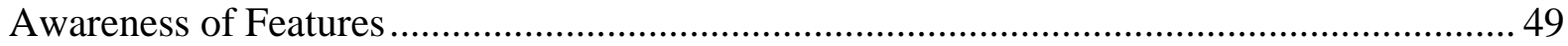

Super-ordinate Theme 4: Challenges for Effective Use of the Innovation ..................................50

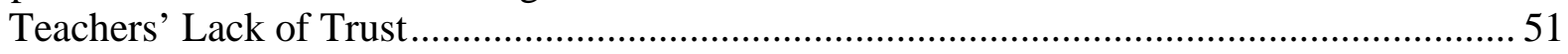

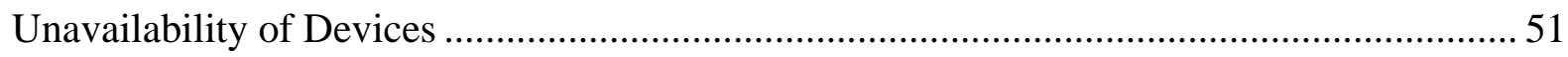

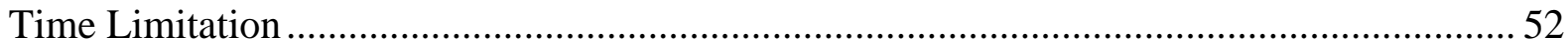

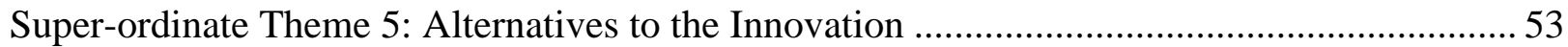

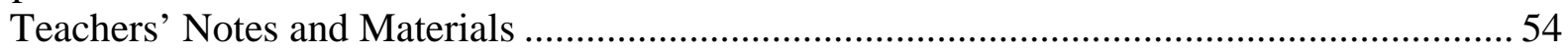

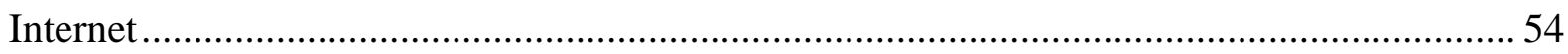

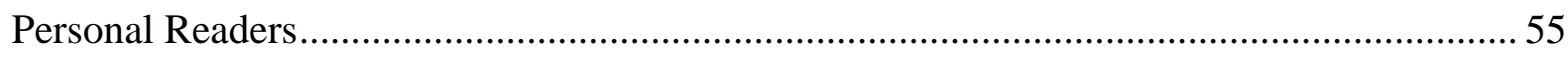

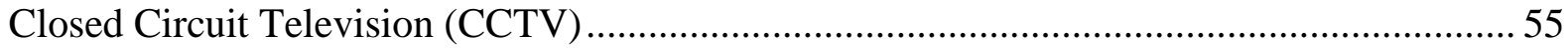

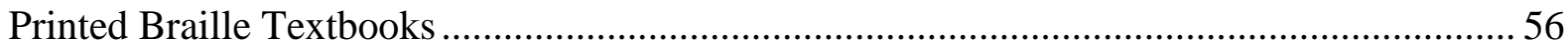

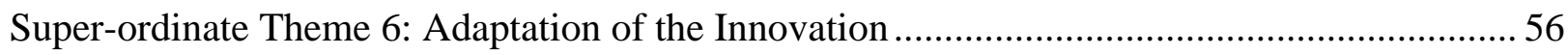

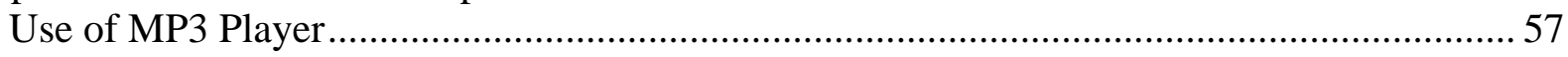

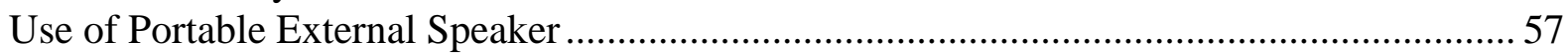

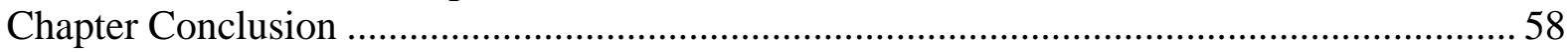

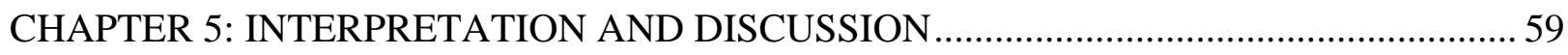

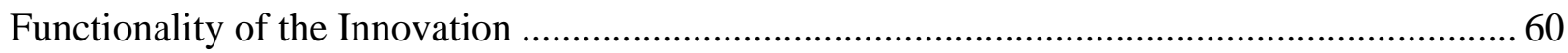

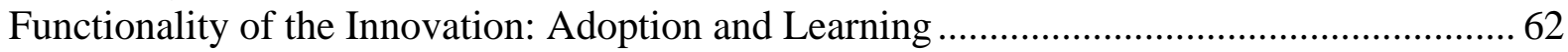

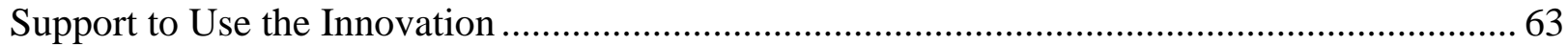

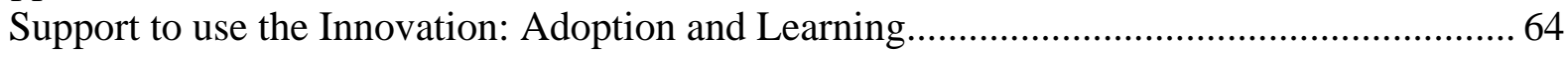

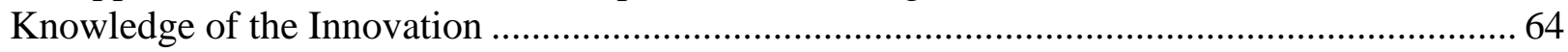

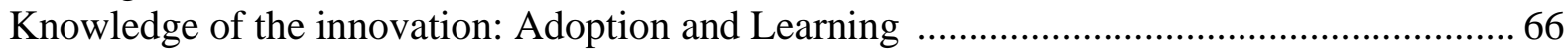

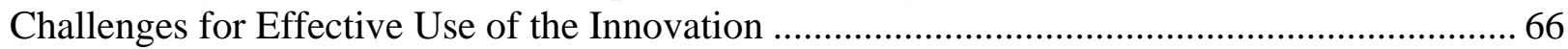

Challenges for effective use of the innovation: Adoption and Learning ..................................6 68

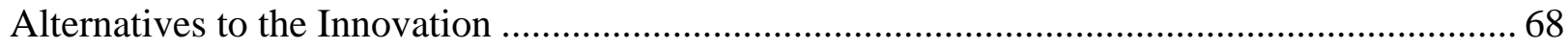

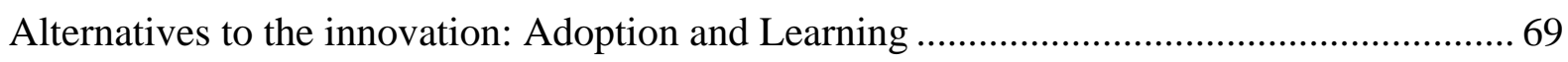

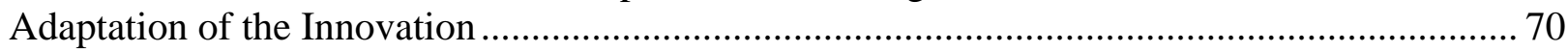

Adaptation of the Innovation: Adoption and Learning........................................................ 70

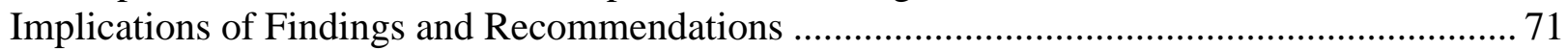

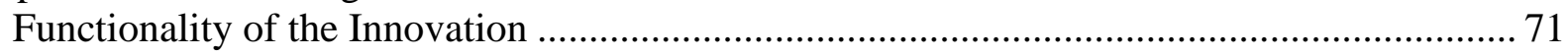

Recommendation to the Ministry of Education............................................................ 71

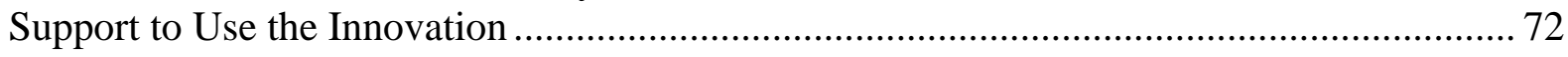

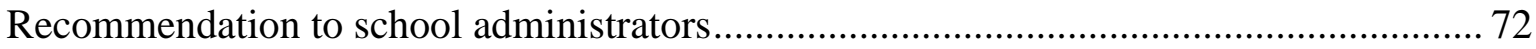

Recommendation to parents and guardians ……………............................................ 72 


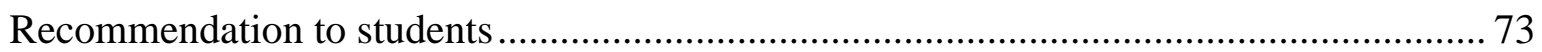

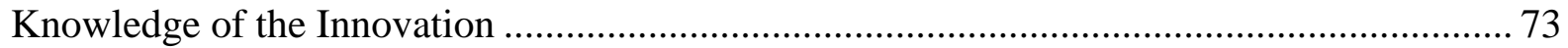

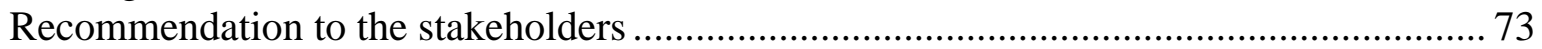

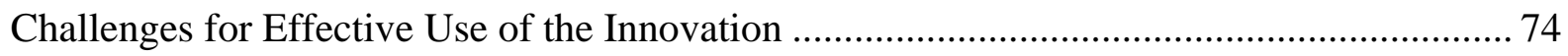

Recommendation to school administrators and teachers ............................................ 74

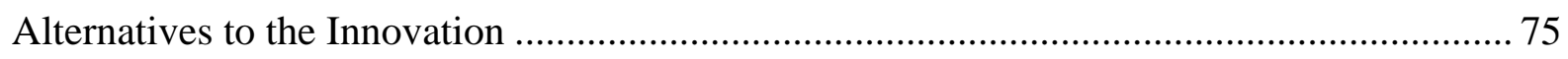

Recommendation to the Ministry of Education............................................................ 75

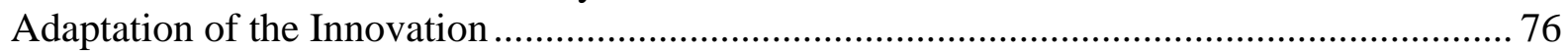

Recommendation to school administrators and teachers ............................................ 76

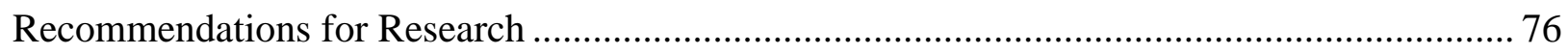

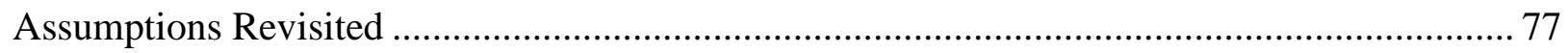

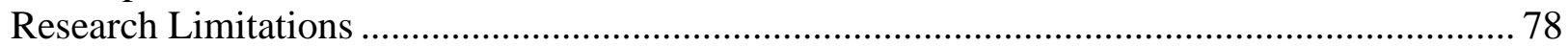

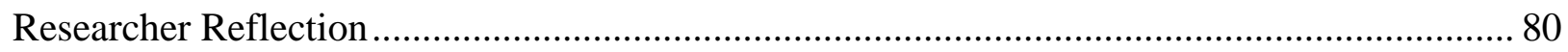

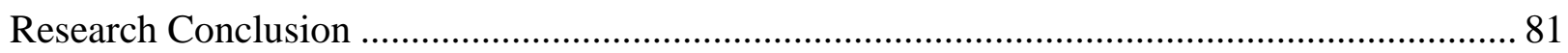

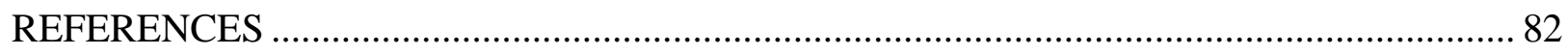

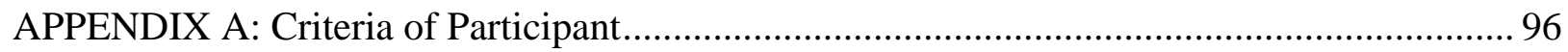

APPENDIX B: Interview Schedule ............................................................................ 97

APPENDIX C: Institutional Review Board Approval ................................................. 98

APPENDIX D: Economic Planning Unit (EPU) Approval Letter ......................................... 99

APPENDIX E: The State Education Department Approval Letter ...................................... 101

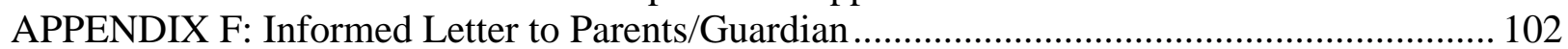

APPENDIX G: Informed Letter to Student.................................................................. 104

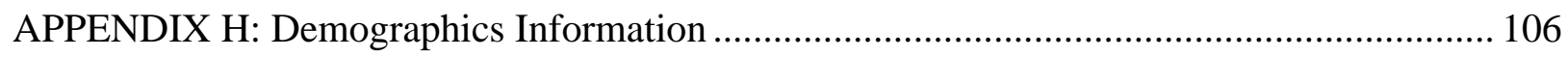

APPENDIX I: Exploratory Comments (Extract) ............................................................ 107

APPENDIX J: Super-ordinate Themes Table (Extract) ..................................................... 109

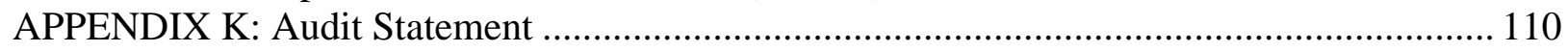




\section{LIST OF TABLES}

1. List of DTTs Usage for Primary Levels .................................................................. 3

2. List of DTTs Usage for Secondary Levels .......................................................... 4

3. Types of Assistive Technology for Students with Visual Impairments .............................. 11

4. Demographics of Student Participants....................................................................... 26

5. Super-Ordinate Themes and Emergent Themes .............................................................. 34 


\section{LIST OF FIGURES}

1. Stages in the Innovation-Decision Process .............................................................. 18

2. Coding network for super-ordinate theme 1 , functionality of the innovation ....................... 35

3. Coding network for super-ordinate theme 2, support to use the innovation ........................ 44

4. Coding network for super-ordinate theme 3, knowledge of the innovation ........................ 47

5. Coding network for super-ordinate theme 4, challenges for effective use of the

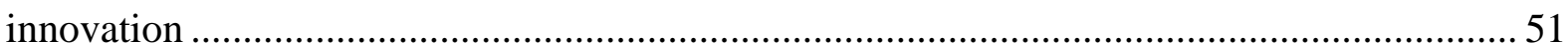

6. Coding network for super-ordinate theme 5, alternatives to the innovation ........................ 54

7. Coding network for super-ordinate theme 6 , adaptation of the innovation .......................... 57 


\section{DEFINITION OF TERMS}

Terms used throughout the study are defined here to ensure clarity of understanding (Bloomberg \& Volpe, 2008).

Adoption: "A decision to make full use of an innovation" (Rogers, 2003, p. 21).

Assistive technology: Refers to the digital talking textbooks (DTTs), which is the digital audio books produced and provided to students with visual impairments by the Ministry of Education, Malaysia.

Blind students: Refers to students who are unable to use printed learning materials except Braille or other non-visual media.

Discontinuance: Refers to "a decision to reject an innovation after it has previously been adopted" (Rogers, 2003, p. 21).

Low vision students: Refers to students who have severe visual impairments but can see under certain conditions. These students may be unable to read printed materials or text at a normal viewing distance, even with the aid of glasses or contact lenses.

Innovation: "An idea, practice, or object that is perceived as new by an individual" (Roger, 2003, p. 12). For this study, innovation refers to the DTTs.

Rejection: “A decision not to adopt the innovation" (Rogers, 2003, p. 21).

Secondary school student: Refers to students ranging in age from thirteen to seventeen years old. 


\section{CHAPTER 1: INTRODUCTION}

In his digital era, rapid computer technology advances provide new options for teaching and learning. These advances make teaching and learning feasible and provide opportunities for teachers and students to access information, lessons, and classes from many sources.

Technology applications such as: speech synthesis, electronic messaging, screen readers, captioned televisions, alternative keyboards, augmentative communication devices, and electronic books are salient to assist students with learning challenges. For these students, the challenges may include visual impairments, hearing impairments, physical disabilities, developmental disabilities, and emotional disturbances (Male, 2003).

\section{Research Problem Statement}

In Malaysia, the Ministry of Education has stated that information, communication, and technology (ICT) are crucial tools to revolutionize the education system. Thus, the Ministry formulated three main policies related to ICT and its importance for education: (a) ICT for all students, as an enabler to reduce the digital gap among schools, (b) ICT as a teaching and learning tool, and (c) ICT as a tool to increase productivity, efficiency, and effectiveness of the management system in schools. These policies are in line with Malaysia's aspiration to become a fully developed nation by the year 2020 (Ministry of Education, 2003).

Since the 1990s, the Ministry spent more than six billion Malaysian Ringgit (two billion U.S. dollars) on ICT in education initiatives including: (a) establishing the Malaysian Smart School, which is a learning institution that has been systemically reinvented in teaching and learning practices and school management to prepare students for the information age; (b) setting up 'MySchoolNet', which is the Ministry's website; (c) promoting ICT literacy in schools; (d) equipping each school with a computer lab; (e) providing digital talking textbooks (DTTs) for 
students with visual impairments; (f) teaching mathematics and science in English; (g) implementing Web TVs, which are online streaming teaching and learning materials; and (h) establishing computer access centers, as an after school hours computer center for students (Ministry of Education Malaysia, 2012).

The Ministry has also highlighted the importance of ICT in education through the improvisation of national short-term and long-term educational planning. As stated in the Educational Development Master Plan 2006-2010, one of the major pillars was to bridge the digital gap among students. In the latest national long-term educational plan, Malaysia Education Blueprint 2013-2025, the Ministry seeks to improve access to education (Ministry of Education, 2012). The efforts to improve include providing Internet access and a virtual learning environment for 10,000 schools across the country, and maximizing use of ICT for distance and self-paced learning.

To provide equal access to technology in education, the Ministry takes into consideration the education needs of diverse learners, including students with visual impairments. In assisting student access, a technology tool that could bridge the digital gap is DTT. Among the rationales underlying the introduction of the DTTs were: (a) to implement the ICT policies in education, (b) to assist students with visual impairments to access information and lessons, and (c) to produce a more conducive teaching and learning environment for students with visual impairments (Textbook Division, 2010).

For the purpose of this study, DTTs refer to electronic textbooks, which are an innovation in learning materials for selected subjects produced by the Ministry. One of the special characteristics of DTTs is the content equivalency to standard printed textbooks. In 2009, the Ministry introduced DTTs for the following subjects: Malay Language, English, 
Islamic Education, Moral Education, and Local Studies to be used by students with visual impairments in primary levels, students aged seven to 12 , as listed in Table 1 . The expiration refers to the DTTs' period of usage, which differed among the subjects. For example, the Malay Language subject for primary level was used from 2009 through 2011.

Table 1

List of DTTs Usage for Primary Levels

\begin{tabular}{lll}
\hline Level & Subject & Expiration \\
\hline Primary School & Malay Language Year 2 & 2011 \\
& Malay Language Year 3 & 2012 \\
& English Year 2 & 2011 \\
& English Year 3 & 2012 \\
& Islamic Education Year 6 & 2015 \\
& Moral Education Year 6 & 2015 \\
& Local Studies Year 6 & 2015 \\
\hline
\end{tabular}

For secondary levels, students aged 13 to 17 , the Ministry introduced DTTs to assist learning for these subjects: Malay Language, English, Islamic Education, Geography, History, and Moral Education as listed in Table 2. 
Table 2

List of DTTs Usage for Secondary Levels

\begin{tabular}{lll}
\hline Level & Subject & Expiration \\
\hline Secondary School & Malay Language Form 1 & 2013 \\
& Malay Language Form 2 & 2014 \\
& Malay Language Form 3 & 2015 \\
& English Form 1 & 2013 \\
& English Form 2 & 2014 \\
& English Form 3 & 2015 \\
Islamic Education Form 3 & 2015 \\
Islamic Education Form 5 & 2017 \\
Geography Form 3 & 2015 \\
History Form 3 & 2015 \\
History Form 5 & 2017 \\
Moral Education Form 3 & 2015 \\
Moral Education Form 5 & \\
\hline
\end{tabular}

DTTs have been used in schools since 2009, including schools for the students with visual impairments. However, there has been no study to date regarding students' experiences using DTTs to assist learning. The Ministry needs to know how effective DTTs are and how their use might be improved to facilitate learning. With this knowledge, they can make better decisions about its use in the future. 


\section{Significance of the Study}

This study is significant as an initial step to ascertain the experiences of students with visual impairments in using DTTs to assist learning. The information conveyed by the students will provide useful feedback to the Ministry for planning, developing, and providing better learning materials for students with visual impairments in the future. The information will also be useful for identifying the challenges of technology adoption among students with visual impairments and for parents to obtain optimal technology devices for their children. Although it is important to be mindful about cost effectiveness of the innovation, it is noteworthy as well for the Ministry to develop and provide suitable learning materials for students. This study is significant for the stakeholders including the Ministry, state education departments, schools, and teachers in gaining information for needs and accountability assessments.

\section{Purpose of the Study and Research Question}

The purpose of this qualitative study is to explore, describe, and interpret the experiences of students with visual impairments use of DTTs. In qualitative inquiry, there are three categories of research questions: (a) descriptive, (b) interpretive, and (c) theoretical (Maxwell, 2005). For this study, the research question was constructed within the interpretive category, which is based on the research purpose. The primary research question for this study is: What factors influence students with visual impairments to adopt or to reject DTTs?

\section{Research Assumptions}

Research assumptions provide a basis for what the researcher believes to be true regarding a topic (Bloomberg \& Volpe, 2008). Three assumptions were identified prior to initiating this study: (a) DTTs are the best learning resources for students with visual impairments, (b) the students with visual impairments experience innovation in a positive way, 
and (c) the students with visual impairments make full use of DTTs to assist their learning. The first assumption focused on the features of DTTs as the best learning resources, which are developed in compliance with DAISY standards. The second assumption highlighted the positive experience by the students with DTTs, and the third assumption concentrated on how students with visual impairments adopt DTTs to assist learning. This assumption is based upon the main purpose of DTTs to help students access lessons.

\section{Research Delimitations}

Delimitations explain the boundaries the researcher imposes prior to initiating a study and are important to narrow the focus of a study (Creswell, 2003). The research delimitations for this study are: (a) the participants were from a secondary school for the blind, (b) the participants were all using DTTs, and (c) the research genre selected by the researcher was an Interpretative Phenomenological Analysis (IPA). There are two secondary schools for the blind in Malaysia. The study was conducted in one of these schools for convenience, as the school is located close to the researcher's home. The aim of this study was to understand students' experiences using DTTs; therefore, students who did not use the DTTs were excluded. To explore students' experiences using the DTTs, the researcher employed an IPA approach. This approach has been widely used to examine major life experiences of people (Smith, Flowers, \& Larkin, 2009).

\section{Theoretical Framework}

Anfara and Mertz (2006) said there are three types of theoretical research frameworks, with a theory that: (a) has less relation to a specific qualitative inquiry, (b) is related to the specific qualitative inquiry, and (c) has more dominant roles than the qualitative inquiry. This

study falls under the first type, less relation to particular qualitative research. Rogers' diffusion of innovation model (2003) was used to enhance understanding concerning the phenomenon 
under investigation. Roger's diffusion model explains how an innovation is diffused in a social system. It offers three valuable insights into the process of social change: (a) what qualities make an innovation diffuse successfully, (b) the importance of peer networks, and (c) understanding the needs of different users. Robinson (2009) reported that this model has been applied in more than 6,000 social science studies exploring the processes of social change.

According to the model, there are five chronological stages that an individual experiences before making a decision to adopt an innovation or not. The stages are called 'the innovationdecision process', which includes the knowledge, persuasion, decision, implementation, and confirmation stages. This study focuses on the persuasion stage, which has a strong connection to the characteristics of the innovation, such as relative advantage, compatibility, complexity, trialability, and observability. From the model, the decision to adopt or to reject a new innovation depends on these attributes of the innovation (Rogers, 2003). Since these attributes have been widely used in research on diffusion of innovation in many fields, the model was applied in this study to explore the experiences of students with visual impairments in using DTTs to assist learning.

\section{Researcher's Background}

This section is important to provide information about the researcher's education, professional experiences, and qualifications to carry out the investigation (Bloomberg \& Volpe, 2008). Prior arrival in the United States, the researcher was a teacher for secondary-level schools in Malaysia. The researcher did not have experience teaching students with disabilities, particularly students with visual impairments; however, his diverse experiences in three different school settings enabled him to assist the students at different levels and help students to succeed in their academic and life endeavors. After five years in different school settings, an opportunity 
to utilize and expand his experience by serving the Ministry under the Textbooks Division was presented. Among his main job specifications at the Division were managing textbook publications, including DTTs and Braille textbooks for the students with visual impairments. At the Ministry, he was exposed to multiple instructional technologies, particularly technologies to assist students with visual impairments.

While serving at this division, the researcher was offered a doctorate scholarship to learn more about the instructional technologies. He proceeded to visit a school for the deaf and blind in Colorado Springs, Colorado. This particular visit provided a new perspective concerning the importance of technologies in assisting learning for students with visual impairments. He learned how technological devices could assist students in accessing information from three learning resources such as printed materials, audio, and Internet. Subsequently, the visit provided inspiration for the researcher to pursue a study to determine factors influencing the adoption and rejection of DTTs among students with visual impairments in Malaysia.

The researcher prepared for this study by acquiring knowledge and skills required for research. Prior to conducting this study, he enrolled in various research classes including Introduction to Research Methods, Measurement Concepts, Quantitative Research Methods, Foundations of Educational Research, Qualitative Research Methods, Qualitative Data Analysis, Seminars on Research Methodology, and Workshops on Nvivo10 for Qualitative Data Analysis. Research knowledge and skills are very important to provide credibility, dependability, and transferability of any study. 


\section{CHAPTER 2: LITERATURE REVIEW}

The purpose of this qualitative study was to explore and understand the experiences of students with visual impairments in using digital talking textbooks (DTTs) to assist learning. The main focus was on the research question: What factors influence students with visual impairments to adopt or reject DTTs? Two basic philosophies are espoused regarding a literature review: (a) not review the literature until data collection is started to avoid biases, or (b) review the literature before a research proposal is formulated (Bloomberg \& Volpe, 2008; Glesne, 2011; Silverman, 2010).

The latter recommendation was utilized, and a review of the literature on innovation and assistive technology for students with visual impairments was conducted prior to preparation of the research proposal to guide the researcher with theories and assumptions. Initial topics of review were the definitions of assistive technology, the benefits of assistive technology, barriers to effective use of assistive technology, digital talking textbooks (DTTs), and diffusion of innovation. This chapter follows this basic outline.

\section{Definitions of Assistive Technology}

There is no definitive definition for assistive technology. The United Nations defines assistive technology as "technology adapted or specially designed to improve the functioning of people with disabilities" (Borg, Lindstrom, \& Larsson, 2009, p. 1863). In the United States, assistive technology refers to "any item, piece of equipment, or product system, whether acquired commercially, modified, or customized, that is used to increase, maintain, or improve functional capabilities of individuals with disabilities" (The Assistive Technology Act, 2004, p. 1710). Hardware, such as screen magnifiers and alternative keyboards, as well as software, such 
as optical character recognition, onscreen keyboards, and voice recognitions, are all types of assistive technology.

Based on general definitions of assistive technology, Blackhurst and Lahm (2000) elaborated that assistive technology devices include the following: mechanical, electronic and microprocessor-based equipment; non-mechanical and non-electronic aids; and specialized instructional materials, services, and strategies that people with disabilities use to: (a) assist learning, (b) make the environment more accessible, (c) compete in the workplace, (d) enhance independence, or (e) improve quality of life. Bryant and Bryant (2003) grouped assistive technologies into seven categories, which include positioning and seating, mobility, augmentative and alternative communication, computer access, adaptive toys and games, adaptive environments, and instructional aids. In contrast, Reed and Lahm (2005) classified assistive technologies into thirteen categories based on the task for which each is useful: (a) computer access, (b) motor aspects of writing, (c) composing written material, (d) communication, (e) reading, (f) learning/studying, (g) math, (h) recreation and leisure, (i) electric aids for daily living, (j) mobility, (k) vision, (l) hearing, and (m) vocational. Sharp (2002) considered services for assessment, training, adaptation, and technical assistance as assistive technology.

The other general classification of assistive technology devices includes a spectrum of equipment, from high to low tech that can be applied in writing, reading, access to computers, communication, mobility, and leisure (Wong \& Cohen, 2011). The low-tech devices do not require onerous training and are inexpensive. Examples of low-tech devices are handheld magnifiers, large print texts, and canes. In contrast, high-tech devices refer to more sophisticated tools requiring special training to use the devices effectively. The devices are considered more 
expensive such as voice recognition, electronic organizers, digital hearing aids, and communication devices with voices (Georgia’s Assistive Technology, 2011).

In educational settings, assistive technology refers to any technological tools or devices that help students with disabilities to access learning materials and perform learning tasks easily. The American Foundation for the Blind classifies the types of assistive technology for students who are blind or low vision into four main categories, as shown in Table 3 (Presley \& D' Andrea, 2008).

Table 3

Types of Assistive Technology for Students with Visual Impairments Types of Technology Devices

Technology for accessing print material large print, reading stand, acetate overlays, lighting, handheld and stand magnifiers, telescopes, video magnification systems, scanning and optical character recognition (OCR) systems, electronic whiteboards, Braille reading, tactile graphics, digital talking books, e-book readers, talking calculators, talking dictionaries.

Technology for accessing electronic large monitor, adjustable monitor arms, cursorinformation

enlarging software, screen magnification software, accessible Personal Digital Assistant (PDA), large print, online dictionaries, refreshable Braille displays, touch tablet, text 
reader, self-voicing applications, e-book reader, digital voice recorder.

Technology for producing written communications felt-tip pen and bold marker, dedicated word processor, imaging software, drawing software, math software and spreadsheets, slate and stylus Braillewriter, electronic Braillewriter, Braille translation software, Braille embosser, accessible PDA

Technology for producing materials in alternate formats
Scanning and optical character recognition (OCR) system, laser print, Braille translation software, Braille embosser, graphics software, fusers and capsule paper, digital and analog audio recording device.

For the purpose of this study, assistive technology refers exclusively to the DTTs, which are designed specifically for students with visual impairments to access print material. These assistive technology devices for accessing print material are provided by the Malaysian Ministry of Education to all students with visual impairments across the nation. 


\section{Benefits of Assistive Technology}

Assistive technology devices have become essential tools for students with learning disabilities. Assistive technology devices such as DTTs allow students to: (a) access educational resources (Beard, Carpenter, \& Johnston, 2011), (b) maximize self-reliance to do tasks (Bryant \& Bryant, 2003), (c) participate in discussions (Cavalier, Feretti, \& Okolo, 1994; Male, 2003), (d) access peer groups (Fisher \& Frey, 2002), and (e) prepare for higher education and future careers (Burgstahler, 2003). In an educational setting, the benefit of using assistive technology devices in teaching and learning has been widely studied in recent years (Hussin, Mohd Nor, \& Suhaimi, 2008; Leporini, 2007; Martins, Steil, \& Todesco, 2004; Pal, Vallauri, \& Tsaran, 2011). Studies showed that assistive technology devices have a positive impact on students with visual impairments' lives, such as motivating students (Cooper \& Nichols, 2007; Kapperman, Sticken, \& Heinze, 2002; Strobel, Fossa, Arthanat, \& Brace, 2006), and developing positive relationships in their academic achievement (Huang \& Russell, 2006; Trucano, 2005).

Studies have been conducted on the effect and usefulness of assistive technology in students with learning disabilities. Scholars found that assistive technology devices have positive impact on students' learning, specifically, increasing reading speeds and comprehension rates (Corn et al., 2002; Howell, 1996; Kennedy, 2002; Merbler, Azar, \& Ulman, 1999). However, most of the studies focused on assistive technology devices for students with autism, severe disabilities, learning disabilities, emotional behavioral disabilities, as well as learning behavioral and emotional disorders. There was a lack of research conducted on other disabilities, especially blindness and partial blindness.

Assistive technology devices are essential for students with visual impairments to enhance learning, cognition, and social development (Sze, Murphy, Smith, \& Yu, 2004; Wong \& 
Cohen, 2011). Devices include Job Access With Speech (JAWS $®)$, talking calculators, audio books, Braille, tactile maps, magnifying glasses, and computer screens, which have improved access to information. By using these devices, students with visual impairments can enhance their learning and gain opportunities for equality in education. For example, screen readers provide opportunities to access current information through the Internet (Coard, 2002), participate in online discussions (Lee \& Templeton, 2008), and develop social networks (Gerber, 2003).

Researchers and practitioners acknowledge the use of assistive technology devices such as Braille note-takers, Braille embossers, screen magnification, and scanners with optical character recognition could change the lives of students with visual impairments. These devices have a positive impact on educational performance, including helping students access and understand three dimensional and non-linear illustrations in math (Cahill, Linehan, McCarthy, Bormans, \& Engelen, 1996), and helping students gain access to curriculum materials generated in printed Braille (Farnsworth \& Luckner, 2008; Fitchen, Asuncion, Barile, Ferraro, \& Wolforth, 2009; Gerber, 2003; Kelly \& Smith, 2011; Roentgen, Gelderblom, Soede, \& Witte, 2009).

Assistive technology devices are not only important for students with visual impairments, but also for the adult population. Jutai, Strong, and Russell-Minda (2009) conducted an exhaustive and meticulous review of 108 studies on vision rehabilitation interventions and assistive technologies for adults aged 19 and above who were blind. They found that nonelectronic optical devices, particularly magnifiers, were the most useful and popular devices for the adults with visual impairments, particularly low vision adults, because these devices are portable and inexpensive. 


\section{Barriers to Effective Use of Assistive Technology}

A number of barriers exist to the successful and effective use of assistive technology devices among people with various disabilities in schools, homes, and communities. The barriers to successful and effective use of devices relate to several factors, such as limited financial resources (Fifield \& Fifield, 1997), high costs of equipment (Wehmeyer, 1998), a lack of knowledge and support from teachers (Abner \& Lahm, 2002; Alper \& Raharinirina, 2006), and eligibility issues for possessing devices (Zhang, 2000).

In the United States, a national survey on abandonment of technology by adults with various disabilities showed that almost one-third of the assistive technology devices were unused due to multiple factors: (a) lack of consideration and willingness to use the devices from the individuals with disability needs; (b) technology tools selected by family members, not the users; (c) complicated design; (d) unreliable equipment; (e) insufficient funding for the assistive technology devices; and (f) lack of technical support (Philips \& Broadnax, 1992; Scherer, 1993; Todis, 1996). In another study, Johnson (2011) concluded that a lack of knowledge and awareness among people with disabilities, reluctance to use the devices, poor device performance, changes in needs or priorities, and feelings of stigmatization were the main reasons for underused assistive technology devices.

A study by Kapperman, Sticken, and Heinze (2002), in both elementary schools and high schools in Illinois, showed that between 59 and 71 percent of the students with visual impairments who had potential to use reading devices did not have opportunities to adopt the assistive technology devices. The lack of opportunities were due to insufficient provision of assistive technology devices, insufficient time to provide training for students, insufficient funds to purchase the assistive technology devices, and lack of appropriate teacher training. In another 
study, it was reported that lack of appropriate training among teachers, high cost of the assistive technology devices, insufficient devices produced, and lack of information about the devices were all barriers to effective use of assistive technology in education. These factors also contributed to high rates of abandonment of assistive technology tools among students (Hasselbring \& Glaser, 2007; Riemer-Reiss \& Wacker, 1999).

Copley and Ziviani (2004) identified six barriers to effective use of assistive technology devices among students with multiple disabilities, including: (a) lack of appropriate staff training and support, (b) negative staff attitudes, (c) inadequate assessment and planning processes, (d) insufficient funding, (e) difficulties procuring and managing equipment, and (f) time constraints. In another study by Leporini (2007), students with visual impairments faced problems when using assistive technology in seeking information, which included lack of context, that screen readers or magnifiers show small portions of content at any one time; overload of information that slows down content exploration; and excessive sequencing, such as long tables making reading distracting. As a result, these barriers caused abandonment or rejection to the innovation.

\section{Digital Talking Textbooks (DTTs)}

Historically, the first talking books were introduced in the 1930s in Britain for soldiers who lost their sight. At that time, the talking books were in the form of tapes played on recorders. As advances in technology improved, these developed into electronic books (e-books) and digital talking textbooks (Coard, 2002; Philips, 2007). Duarte and Carrico (2007) listed the features of the DTTs, which include: (a) a visual display is not needed, (b) multiple playback speeds, (c) content accessible at a fine level of detail, (d) usable table of contents, (e) easy skips, 
(f) ability to manage notes, (g) setting and labeling bookmarks, (h) fast forward and reverse, and (i) presentation of visual contents in alternative formats.

In Malaysia, the Ministry of Education introduced DTTs for selected subjects into the school system in 2009. The DTTs were designed specifically for students with visual impairments based on the Digital Accessible Information System (DAISY) standard format. The standard format provides unique features such as advanced navigation, bookmarks, better sound quality than tape formats, and large amounts of content. The students with visual impairments may read the DTTs with stand-alone players, playback software, and MP3 players.

The DTTs offer many advantages to students with visual impairments. The devices allow students to easily access lessons by locating a specific topics or chapters quickly, placing bookmarks for future reference, adjusting text size, changing the font, and listening to audio (Leporini, 2007). DTTs researchers believed that these learning materials could overcome most problems derived from printed textbooks, as DTTs offer interactive materials, allow locating specific contents, and skipping and returning to the content easily (Duarte \& Carrico, 2007; Moreno \& Mayer, 2000).

\section{Diffusion of Innovation: Digital Talking Textbooks}

Rogers' diffusion of innovation model (2003) has been widely used in various research studies by scholars on technology and adoption of innovation. Based on the model, there are five chronological stages an individual needs to experience before making a decision to adopt or reject an innovation. This adoption decision-making process could be applied to a new technology tool to assist students with visual impairments in learning. The stages are known as "the innovation-decision process." Figure 1 shows the five stages in the innovation-decision. 


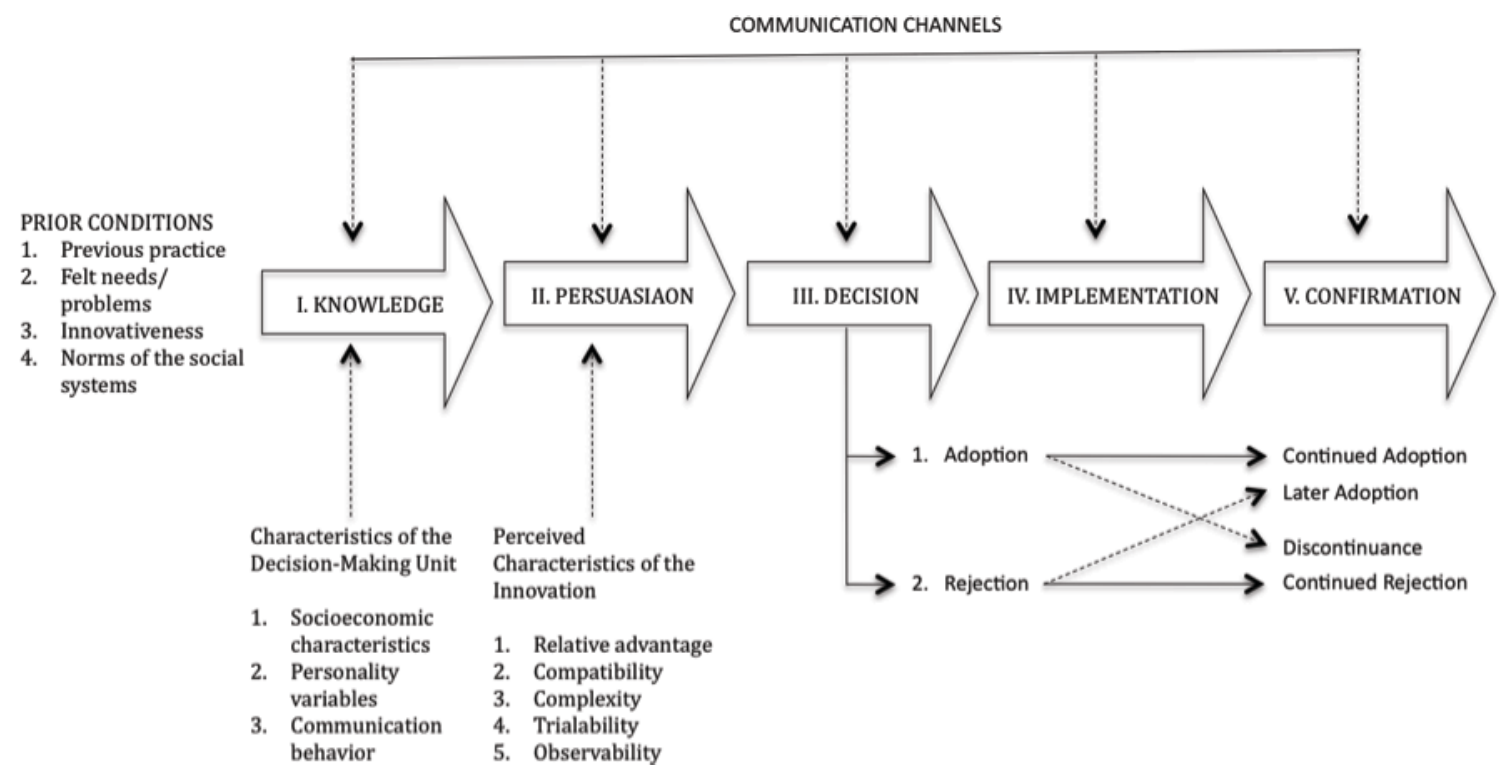

Figure 1: Stages in the Innovation-Decision Process (Rogers, 2003, p. 170).

The first stage in the innovation-decision process is knowledge. It occurs when an individual is exposed to the existence of an innovation and has gained understanding of the innovation's function. In general, there are three types of knowledge about a new innovation: (a) awareness-knowledge, which is information about the existence of an innovation; (b) how-to knowledge, which is information on how to use an innovation correctly; (c) principlesknowledge, which is information on how an innovation works. The decision to adopt or reject a new innovation depends on an individual's socioeconomic position, personality, and communication behavior (Rogers, 2003). Some innovations are expensive and require special tools or equipment to adopt. Personality characteristics, such as attitude toward change and selfefficacy, as well as communication behaviors, such as interpersonal networks, may also influence an individual's decision to adopt or reject an innovation (Rogers, 2003).

The second stage is persuasion. This stage occurs when an individual develops a favorable or unfavorable attitude toward an innovation. This process has a strong connection to 
the characteristics of the innovation, which include: (1) relative advantage, (2) compatibility, (3) complexity, (4) trialability, and (5) observability. The decision to adopt or reject a new innovation depends on these attributes of innovation. These attributes have been widely studied in research on diffusion of innovation (Rogers, 2003). The first attribute, relative advantage, is "the degree to which an innovation is perceived as being better than the idea it supersedes" (Rogers, 2003, p. 229). Benefits could be in terms of economy, social status, reducing uneasiness, and saving of time and effort. A significant body of research from different disciplines such as agriculture, family planning, and health indicated that relative advantage has a positive relationship with the rate of adoption of various innovations (Rogers, 2003).

The second attribute, compatibility, is "the degree to which an innovation is perceived as consistent with the existing value, past experiences, and needs of potential adopters" (Rogers, 2003, p. 240). For innovation in learning materials, the new idea may or may not be compatible with students' socio-cultural values, beliefs, or needs for the new technology. The third attribute is complexity. Rogers (2003) defined complexity as "the degree to which an innovation is perceived as relatively difficult to understand and use" (p. 257). One of the hurdles for an individual to adopt a new innovation is its complexity. If the innovation is too complicated or confusing, it takes longer time to achieve acceptance to the innovation and might lead toward rejection (Rogers, 2003).

The fourth attribute, trialability, is "the degree to which an innovation may be experimented with on a limited basis" (Rogers, 2003, p. 258). It refers to the period of time allowing the adopter of the technology to experience the innovation. Based on the researcher's experience, trialability has not been a practice in the Malaysian educational setting. Students are not given the chance to experience new learning materials due to insufficient time and budget, 
either from the learning materials' developers or school administrations. Consequently, new learning materials could be totally adopted or rejected by these students. The last attribute, observability, refers to "the degree to which the results of an innovation are visible to others" (Rogers, 2003, p. 258). In this study, even though students are not able to observe how the new innovation works for them, they can share their personal experiences in using the innovation with others through both verbal and written forms.

The third stage in the innovation-decision process is decision. In this stage, an individual engages in activities that lead to a decision to adopt or reject the innovation. To make a decision upon adoption or rejection, an individual has to experience the new innovation. A positive experience and the advantages of the innovation may stimulate the adoption. On the other hand, a negative experience and difficulty may lead toward rejection of the innovation. The fourth stage is implementation. It typically follows the decision stage directly and "occurs when an individual puts an innovation to use" (Rogers, 2003, p. 179). The stage also depends on the characteristics of the new learning materials itself, as well the role of schools' administration and teachers.

The last stage in the innovation-decision process is confirmation. At this stage, "the individual seeks reinforcement for the decision already made" (Rogers, 2003, p. 189). Within the Malaysian educational context, confirmation stage occurs when students put efforts to strengthen the innovation-decision that they made. They may change their decision in using the innovation to discontinuance, which is the rejection after adoption of the innovation, if they find conflicts of interest in using the innovation. 


\section{Chapter Conclusion}

Based reviewing the literature, a gap in empirical studies concerning the experiences of students with visual impairments using innovations seems to exist. There were studies focused on many types of assistive technologies; however, thus far, no specific research was identified in Malaysia about how these students experience using the innovation to assist learning, particularly with DTTs. 


\section{CHAPTER 3: METHODOLOGY}

Methodology is a set of guidelines that direct the researcher's work. It determines a method for the researcher to produce data for analysis and enables the researcher to interpret data sensibly and with insights. Generally in a study, the selection of methodology is primarily based on the phenomenon under investigation, purpose of study, theory base, and character of data (Roberts, 2010). For this study, the selection of methodology was based on the phenomenon under investigation and purpose of study.

The purpose of this qualitative study was to conduct an interpretative phenomenological analysis (IPA) to explore and understand the experiences of students with visual impairments in using digital talking textbooks (DTTs) to assist learning. To explore the phenomenon, the researcher focused on one primary research question: What are factors influencing students with visual impairments to adopt or reject DTTs? This chapter describes the research methodology of the study, which includes approach, strategy of inquiry and rationale, researcher's role, population and participants, sampling procedures, instrumentation, translation procedures, data analysis, and trustworthiness.

\section{Research Approach}

A qualitative study involves an interpretive and naturalistic approach (Denzin \& Lincoln, 2000). The approach demands that the phenomenon under investigation be examined with an assumption that nothing is irrelevant (Bogdan \& Biklen, 2007; Denzin \& Lincoln, 2000). For

this study, a qualitative research approach is fitting for the research question. The purpose of this study was to investigate the experiences of students with visual impairments in using DTTs. To explore students' lived experiences, the researcher employed an interpretive approach, which is associated with the hermeneutic tradition. This tradition encourages the researcher to seek in- 
depth understanding on a phenomenon under investigation by interpreting the meanings of interactions, actions, and objects for the students. This perspective posits that the way to understand social reality is from the perspective of students who are involved in the study, as Martin Heidegger asserted, understanding is inseparable from the human condition (Peshkin, 2000; Smith, Flowers, \& Larkin, 2009).

\section{Strategy of Inquiry and Rationale}

This study applied an IPA as the strategy of inquiry. It is a dynamic process where the researcher plays an active role in the study. This strategy of inquiry seeks to explore and understand students' lived experiences. The IPA assumes "data can tell us something about people's involvement in and orientation toward the world, and/or about how they make sense of this" (Smith et al., 2009, p. 46).

There are three major theoretical underpinning of IPA: (a) phenomenology, (b) hermeneutics, and (c) idiography. Phenomenology focuses on the essence of human experience and shows how complex meanings are built upon units of experience.

It assumes that there is an essence of shared experiences, and the essences are bracketed, analyzed, and compared to identify the essence of the phenomenon (Merriam, 2002). In this study, bracketing did not frequently occur throughout the data collection process; as the researcher kept a reflective journal to record his experiences, personal assumptions, thoughts, feelings, motives, rationales, and views. Bracketing allowed the researcher to be mindful of the value-bound inquiry issues (Smith et al., 2009).

Hermeneutics is the theory of interpretation. It involves a dynamic relationship between the parts and the whole at all levels. The researcher must look at the whole to understand any given part, and must look at the parts to understand the whole (Smith et al., 2009). In this 
process, the researcher moves back and forth through the data instead of going through the data step-by-step. Idiography focuses on the particular. As with an idiographic approach, IPA starts with a detailed and complete examination of one case and then moves on to the next case. The researcher is able to analyze for reoccurring themes only after all the cases are examined (Willig, 2008).

Therefore, in conducting this study, the researcher decided to use an IPA to answer the research inquiry. This method has proven useful and relevant in educational settings such as colleges and schools, to explain experiences of students who are engaged in any experiences throughout their lives (Seidman, 1998; Smith et al., 2009). Hence, the IPA enables the researcher to interpret how students with visual impairments make sense of what they experience from using DTTs to assist learning.

\section{Researcher's Roles}

In qualitative research, the researcher usually engages in rigorous experiences with participants (Creswell, 2009). For this study, the researcher engaged in a theory of interpretation because the researcher is trying to make sense of what the participant is trying to understand of the situation that is happening to them (Smith et al., 2009). The researcher was the primary instrument for data collection and analysis. The researcher played an active role during interviews and member check sessions to get the students with visual impairments' perspectives of their experiences through the process of interpretation.

\section{Population and Participants}

The research population consisted of the students with visual impairments, ages from 13 to 17 in one special school for the visually impaired in Malaysia. These students have been provided the DTTs for selected subjects since 2009, which include Malay Language, English, 
History, and Islamic Education and used the innovation to assist learning. In the 2012 school year, there were 140 students in this secondary school with diversity in age, sex, race, and type of visual impairments.

The aim of an IPA study is to gain better understanding of a phenomenon, which can include an event, process, or relationship of particular people in a particular context (Smith et al., 2009; Willig, 2008). In qualitative research, sample size depends on the particular research inquiry, purpose, logistics, and credibility (Patton, 2002). Theoretically, qualitative researchers work with small and purposively selected samples to gain in-depth understandings of a phenomenon under investigation (Glesne, 2011; Hesse-Biber \& Leavy, 2011; Merriam, 2009). The aim of IPA study is "to say something in detail about the perceptions and understanding of this particular group, rather than prematurely make more general claims" (Smith \& Osborn, 2008, p. 55).

\section{Sampling Procedures}

For this study, the participants were selected based on purposive sampling. Purposive sampling identifies the characteristics of a population and tries to find participants based on the specified characteristics (Johnson \& Christensen, 2012; Patton, 2002). The participant's characteristics were blind and low vision, ages 13 to 17, male and female, who had received DTTs for at least one subject (see APPENDIX A). The researcher requested the school administrator to select the students based on the provided specific characteristics determined as general guidelines for selection. At the end of the selection phase, the administrator identified and selected 12 students and provided the selected list of students to the researcher. Table 4 shows demographic information of these students. 
Table 4

Demographics of Student Participants

\begin{tabular}{|c|c|c|c|}
\hline Pseudonym & Age & Gender & Type of visual impairments \\
\hline Naim & 17 & Male & Low vision \\
\hline Zaiful & 17 & Male & Low vision \\
\hline Daniel & 17 & Male & Blind \\
\hline Aziz & 17 & Male & Blind \\
\hline Teh & 17 & Female & Blind \\
\hline Mirul & 17 & Male & Blind \\
\hline Celine & 15 & Female & Blind \\
\hline Basyirah & 15 & Female & Blind \\
\hline Ruddin & 15 & Male & Blind \\
\hline Hong & 15 & Male & Blind \\
\hline Enn & 15 & Male & Low vision \\
\hline Ning & 15 & Female & Low vision \\
\hline
\end{tabular}

\section{Instrumentation}

In IPA study, the researcher is required to enter the life-world of the research participant to seek a detailed and first-person account of human experiences (Willig, 2008). Thus, an indepth interview is the best tool to capture the participants' experiences. The principle of this type of interview is to seek information and understanding of participants' life experiences (Gubrium \& Holstein, 2002; Seidman, 1998). In addition, interviews are useful in accessing students' experiences and have been used successfully with students from pre-school age through high school age (Greene \& Hogan, 2005; Gubrium \& Holstein, 2002). 
The researcher in this study conducted semi-structured interviews to explore the students' experiences in using DTTs. To guide the researcher conducting the interviews with the participants, a set of interview questions was developed (see APPENDIX B). The aim of the interview was to facilitate a comfortable interaction with the students, to encourage them to provide a detailed account of the experiences under investigation, and "to provide cues when the participant has difficulties" (Smith \& Osborn, 2008, p. 64). The guiding interview questions were developed to be consistent with the purpose of the study and the primary research question.

\section{Data Collection Procedures}

After getting approval from the Institutional Review Board (see APPENDIX C) to conduct the study, the researcher contacted the Economic Planning Unit and the Ministry of Education of Malaysia, as well as the State Education Department to obtain permission to enter the particular school as a research site. Upon getting approval from the Economic Planning Unit (see APPENDIX D) and the State Education Department (see APPENDIX E), the researcher contacted and informed the school principal regarding the study. The researcher met the principal a week before the interview sessions began and provided brief details of the study. The researcher requested the principal to hand out the informed consent letter to each parent (see APPENDIX F) and to each selected student (see APPENDIX G).

Data were collected through one-on-one semi-structured interviews. The interviews were conducted by the researcher toward the end of the first semester of the school year. The procedures of data collection were as follows:

(a) Prior to the in-depth interview session, each student was asked to answer the demographic information (see APPENDIX $\mathrm{H}$ ) and give consent to audio-record the interview session. 
(b) During the individual semi-structured interview, the researcher used the interview questions to explore the participant's experience in using DTTs.

(c) All interviews were conducted in the Learning Resources Room of the school.

(d) Each individual semi-structured interview was recorded using a digital audio recorder.

(e) At the end of each interview session, each student was informed about the individual member check session the following week.

(f) During the member check sessions, the researcher read through each interview transcript to each student. Each student listened, made adjustments, and confirmed that the transcription illustrated the experience that he/she wanted to convey during the interview.

\section{Translation Procedures}

The interviews were conducted in Malay, which is the Malaysian national language, and transcribed literally in Malay by the researcher. After member check sessions were conducted, the transcripts were translated into English with the assistance of an English teacher, who obtained a master's level education in Teaching English as a Second Language (TESL). The researcher kept the anonymity of each participant's information and background, including name, sex, age, as well as the research setting, from the translator. The researcher reviewed the English version of the interview transcripts, to ensure the interviews were all translated correctly, prior to uploading them into the qualitative data analysis software, NVivo10.

\section{Data Analysis}

The researcher must engage with the data actively to gain contextual meaning of the phenomenon under investigation (Willig, 2008). In an IPA study, the researcher works with transcripts or texts generated from research participants. This study employed the heuristic framework for analysis of a single case as suggested by Smith et al. (2009). It began with 
analyzing the first student's transcript thoroughly, then moving to the second transcript, third transcript, and so on. There are six steps in IPA data analysis procedures: (1) reading and rereading the text or transcripts, (2) doing initial noting, (3) developing emergent themes, (4) searching for connections across emergent themes, (5) moving to the next participant, and (6) looking for patterns across participants. These six steps are highly recommended by the IPA experts when doing an IPA study for the first time and were followed in this study (Smith et al., 2009).

For data analysis, the researcher used NVivo10. The researcher performed the first and second steps concurrently. The researcher read each transcript several times and made exploratory comments on the transcripts. Smith et al. (2009) mentioned, "There are no rules about what is commented upon" (p. 83). All exploratory comments at this stage were recorded in the 'Annotations' section of the NVivo software (see APPENDIX I).

During the third step, the researcher analyzed the exploratory comments to identify the emerging themes within each section of the transcripts. The most important idea in this stage was that themes "capture something about the essential quality of what is represented by the texts" (Willig, 2008, p. 58). The emergent themes were recorded in brackets \{\} adjacent to the exploratory comments. The emerging themes were then clustered in the fourth step of data analysis and the researcher listed all the identified themes and clustered them based on 'natural clusters of concepts' and 'hierarchical relationship.' This process required the researcher to move back and forth between the lists of emerging themes and involved charting the development of how the researcher thought the themes could fit together.

The fifth step of data analysis was moving to the next case. The researcher moved to the next student's interview transcript, and repeated the process as performed with the data from the 
first student's interview transcript. In this study, as suggested by Smith et al. (2009), the researcher analyzed the first interview transcript by the student who provided the most comprehensive information on the phenomenon under investigation. Therefore, the order of student's interview transcripts does not follow the order in which the student's were interviewed. The remaining students' interview transcripts were analyzed using the same procedure, one at a time. The last step was looking for patterns across cases. The researcher developed a master table of themes, which included the cluster and subordinate themes with evidence from the transcripts such as quotations and paragraph numbers (see APPENDIX J). When the data analysis procedures were all completed, the researcher reported the results in the emergent findings section of this dissertation.

\section{Trustworthiness}

Trustworthiness or research validity in a qualitative study refers to "the degree to which it is accepted as sound, legitimate, and authoritative by people with an interest in research finding include other researchers, policy-makers, lay public, and practitioners who use the research" (Yardley, 2008, p. 235). According to Johnson and Christensen (2012), research validity in a qualitative study usually corresponds to what is "plausible, credible, trustworthy, and therefore defensible" (p. 264). They classify the trustworthiness of qualitative study into: (a) descriptive validity, (b) interpretative validity, and (c) theoretical validity.

For this study, the researcher employed the interpretative validity strategies to maximize the trustworthiness of the study. As discussed by Johnson and Christensen (2012), interpretative validity refers to "the degree to which the research participants' viewpoints, thoughts, feelings, intentions, and experiences are accurately understood by the qualitative researcher and portrayed in the research report" (p. 265). The researcher applied the suggested strategies, did member 
checking, and used low-inference descriptors to obtain interpretative validity. Through member checks, the researcher read the transcripts to the students and requested they make adjustments and confirmed the transcriptions illustrated the experiences that they wanted to convey. According to Smith (2008), students' adjustments and confirmation on the transcripts, also known as 'respondent validation', are crucial approaches of involving participants to "ensuring that participants' views are not misrepresented" (p. 242).

As another strategy for reliability, the researcher checked the interview transcripts to avoid apparent mistakes during transcription as suggested by Gibbs (2008). During the transcript-checking, the researcher read and reread the transcripts and listened to the recorded interviews at the same time. The other strategy to obtain interpretative validity was by using many low-inference descriptors, such as direct quotations in the research report. Utilizing this strategy, both the researcher and readers can experience the participants' world.

To ensure the meaning of codes were consistent, the researcher employed intra-rater strategy to recode some of the data as suggested by Creswell (2009). The researcher coded the data and left the analysis for a certain period of time; and later, the researcher came back and recoded the data and compared the two sets of coded materials. When comparing the two sets of coded materials and found the consistency of codes, the researcher knew where the coded texts should be clustered under any possible emergent themes.

An independent audit was conducted to ensure the researcher followed the IPA procedures. For this study, a post-doctoral scholar at the University of Wyoming was appointed as an independent auditor to review and audit the study, including interviews transcripts, theme development process, theme tables, and final report. The independent auditor was requested to follow the IPA procedures based on the research question and purpose of this study (see 
APPENDIX K). As suggested by Smith et al. (2009), the independent audit was conducted not to present consensus about a study or to represent the truth; rather, to inform how systematically and transparently the study has been conducted.

Throughout the reviewing and auditing process, the researcher and the independent auditor worked together to go through each phase and content of the study. Questions raised by the auditor to the researcher were clarified, which helped the researcher refine his work on each phase; thus, produced a more readable and reliable report. The majority of the independent auditor's questions were raised during the theme development process due to use of Nvivo10. As noted previously, not many IPA researchers use qualitative software to analyze data, and novice IPA researchers are advised to not use the software for data analysis (Smith et al., 2009). Therefore, the majority of the independent auditor's questions were to clarify how the researcher adapted the 'hard copy three columns table' (which included emergent themes, original transcripts, and exploratory comments) into the Nvivo10 software.

\section{Chapter Conclusion}

To explore the students with visual impairments' experiences in using DTTs, an IPA was chosen as the approach to answer the research inquiry. Twelve students with visual impairments who received DTTs were interviewed. The six steps of IPA data analysis procedures were employed to understand, describe, and interpret the experiences of the students using the DTTs. Throughout the study, the researcher attempted to adapt the IPA guidelines to ensure the quality of the findings. 


\section{CHAPTER 4: EMERGENT FINDINGS}

To answer the inquiry of this study, face-to-face, one-on-one semi-structured interviews were conducted with 12 students with visual impairments in a special school for the blind. Analysis of the students' interview transcripts revealed 23 emergent themes, which were clustered into six super-ordinate themes: (1) functionality of the innovation, (2) support to use the innovation, (3) knowledge of the innovation, (4) challenges for effective use of the innovation, (5) alternative to the innovation, and (6) adaptation of the innovation (see Table 5).

Although there are no specific guidelines to write up the IPA findings, Smith (2004) suggested two broad presentation strategies: (a) report the emergent themes in 'finding' or 'result' section without link to literature, and (b) discuss the emergent themes and the extant literature in a single section 'result and discussion'. The main focus of this chapter is to analyze what the students said or experienced "without reference to the extant literature" (Smith, Flowers, \& Larkin, 2012, p. 112). The researcher presents the themes that emerged from the IPA analysis of the students' experiences with DTTs.

To support the super-ordinate themes and emergent themes, the researcher used verbatim extracts from the interview transcripts. The researcher highlighted students' original words and let the voices of the students emerge. In rare cases where clarification or modification was needed to improve understanding or readability of the text, the researcher made minimal changes by adding text in brackets within the students' quotations. The researcher used pseudonyms for each of the 12 students to protect their anonymity. 
Table 5

Super-Ordinate Themes and Emergent Themes

\begin{tabular}{|c|c|}
\hline Super-ordinate themes & Emergent themes \\
\hline \multirow[t]{5}{*}{ Functionality of the innovation } & Usability \\
\hline & Comfortableness with the innovation \\
\hline & Difficulty of the innovation \\
\hline & Usefulness of the innovation \\
\hline & User-friendliness \\
\hline \multirow[t]{4}{*}{ Support to use the innovation } & Peers' support \\
\hline & Teachers' support \\
\hline & Self-driven behavior \\
\hline & Parents' support \\
\hline \multirow[t]{4}{*}{ Knowledge of the innovation } & Know the purpose of the innovation \\
\hline & Familiarity with the innovation \\
\hline & Sources of information \\
\hline & Awareness of features \\
\hline \multirow{3}{*}{$\begin{array}{l}\text { Challenges for effective use of the } \\
\text { innovation }\end{array}$} & Teachers' lack of trust \\
\hline & Unavailability of the devices \\
\hline & Time limitation \\
\hline \multirow[t]{4}{*}{ Alternatives to the innovation } & Teacher's notes and materials \\
\hline & Internet \\
\hline & Personal reader \\
\hline & Close circuit television (CCTV) \\
\hline
\end{tabular}


Printed Braille textbook

Adaptation of the innovation Use of MP3 player

Use of portable external speaker

\section{Super-ordinate Theme 1: Functionality of the Innovation}

The first super-ordinate theme, functionality of the innovation, was identified as the most dominant theme from the data. The functionality of the DTTs refers to the DTTs' operation that can be run on a computer or other devices. The students viewed the functionality of the DTTs to have an influence on their decision to adopt or reject the technology. Figure 2 demonstrates the coding network the researcher developed using the qualitative data analysis software. The octagon in the middle of the chart represents the super-ordinate theme, functionality of the innovation. The five emergent themes: (a) usability, (b) comfortableness with the innovation, (c) difficulty of the innovation, (d) usefulness of the innovation, and (e) user-friendliness, are represented around the super-ordinate theme.

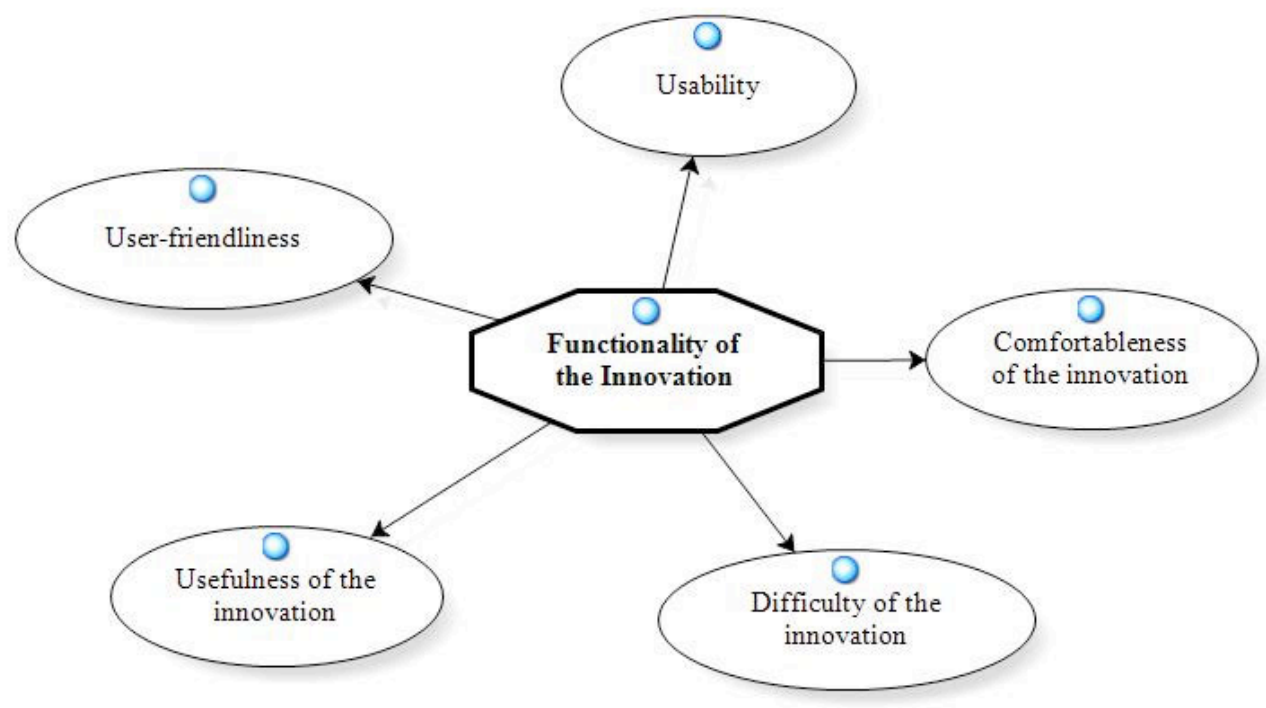

Figure 2. Coding network for super-ordinate theme 1, functionality of the innovation. 


\section{Usability}

The students viewed usability as the factor influencing their interest in using the innovation. Usability refers to the ability of DTTs to be used with a specified hardware and software and fulfill the user's learning needs. Generally, participants perceived the DTTs as usable with the existing applications and software, hardware players, their learning needs, and subjects' need. Rejection of the innovation among students occurred when they recognized the DTTs were not usable with specific devices.

Usability with the existing applications and software. Some students seemed to have common perceptions on the usability of the DTTs to the installed applications and software. For example, Teh, Naim, and Daniel acknowledged that the DTTs were usable with the media player application installed on their computers. As Teh stated, "I could play the CD [digital talking textbooks] on the laptop." Naim shared, "I use media player software that is already installed in my computer." Daniel, who received a subsidized laptop with the media player application installed under the 1Malaysia Program, said that the DTTs were usable with the application in his laptop. He said, "I use laptop...I bring my laptop into the classroom."

In addition, the DTTs are usable with the dedicated software, FSReader ${ }^{\mathrm{TM}}$. The students regarded this software, which comes with the Job Access With Speech (JAWS®) screen reader, as a powerful reading navigation tool for students. These students acknowledged its usability with the DTTs, as Enn mentioned, "With the computer, I access the digital talking textbooks by the FSReader ${ }^{\mathrm{TM}}$...the software for the visually impaired people. I also use a speaker that can use a thumb drive, concurrently." Ruddin said, "I use software FSReader ${ }^{\mathrm{TM}}$ to listen to the contents of the digital talking textbooks; therefore, I can easily move back and forth to listen to the different chapters." 
Usability with the hardware players. One of the great assistive tools for print-disabled and auditory learners is the Digital Accessible Information System (DAISY) hardware player. Hong was the only participant who owned the player and used the device to access the contents of the DTTs. He concluded that the DTTs were readable by the player, "I use the DAISY player to listen to the books [DTTs]." Hong further claimed, "Personally, I like the DAISY player. It is easier to fast-forward and stop. It can be bookmarked too." The DTTs were also readable by the MP3 player. As Teh mentioned, "I could listen by using the MP3 player." Naim also concluded, "The digital talking textbooks actually come in mp3 files. Thus, [the digital talking textbooks] are readable by the media player."

Usability with the student's needs. The relevancy of the DTTs with students' needs is identified as a catalyst to adopt the innovation. Some students described the DTTs as fulfilling their education needs. Naim justified one of his education needs as "One of the reasons [to use the digital talking textbooks] was my eyes could not see clearly if I were to read from the regular textbooks." He acknowledged the advantage of using the DTTs compared to the regular textbooks, "Moreover, if I were to read from the regular textbooks, eventually my eyes would easily get tired and I become sleepy, resulting from the very small characters on the regular textbooks."

For those who were unable to read regular textbooks or dislike reading, the DTTs served their needs. Zaiful and Daniel both expressed that the innovation is a perfect learning tool. Zaiful said, "For those who do not really enjoy reading, then the digital talking textbooks would be the perfect choice." Subsequently he also said, "Too much of reading from the regular textbooks might cause me boredom." Daniel clarified, "It may also be useful for those who do not really have interest in reading...instead, they might just want to listen to the contents and gain the knowledge." Aziz supported this thought, "I think it is a very suitable assistive tool for 
learning...specifically for those who do not have textbooks and unable to read. The innovation really helps the students to comprehend the contents in the syllabus."

For students who are interested in learning through audio, the DTTs fulfilled their needs. For instance, Hong emphasized, "I like the audio stuff and have so much keen in it." Zaiful also provided his insight, "Frankly speaking, I do not really enjoy reading, I prefer listening. It is a lot easier to comprehend the subject matters by listening to its contents."

Usability with the subject matter. According to the students, the usability for the subject matter and learning tasks influenced their interest in adopting the DTTs. However, for certain subjects such as science and languages, the students found the DTTs were not useful. Daniel said, "For specific subjects such as science that has a lot of theoretical explanations and pictures, I think the digital talking textbooks are not suitable to aid the teaching and learning activities." Similarly Basyirah and Ning, who both experienced the DTTs for the Malay Language subject, agreed the innovation was not relevant for that particular subject, Basyirah said, "It is not that feasible to be used [for the language subjects]. I would rather say...it is not suitable at all." Meanwhile, Ning said the DTTs were "Not that feasible...because for the Malay Language, I need to know the correct spelling of the words, and I never feel comfortable and confident with the digital talking textbooks."

Several students adopted the DTTs and viewed the innovation as appropriate for subjects that do not have Braille textbooks, such as Islamic Education and Literature. Celine thought, "The digital talking textbooks are perhaps very suitable for the literature because the subject does not have Braille textbooks available." Teh supported her opinion, "There is no Braille textbook for Islamic Education....and there is also no other reading material to assist learning for that 
subject." Mirul similarly mentioned, "One of the reasons [to use DTT] in Islamic Education...we do not have any other textbooks such as the Braille textbooks."

\section{Comfortableness of the Innovation}

Another significant theme influencing the students to adopt or to reject the DTTs is facilitation of the innovation. Several students pointed out that they were comfortable with the DTTs. Enn expressed being comfortable using the DTTs, "We do not have to read anymore, all we need to do is just listen to the digital talking textbooks." In addition, Naim declared:

Essentially, it would be easier for me to use the digital talking textbooks. I do not have to strain my eyes to read the contents from the regular textbooks then...we just need to listen to the contents. With the regular textbooks, we need to use magnifier to read the contents.

Additionally, some students reported that they were not comfortable with the content delivery of the DTTs, as Zaiful asserted, "I can doze off while listening to the voices." Furthermore, Daniel strongly stated, "I do not feel quite comfortable...as I said, it is because of the contents' instructions and the voices used to convey the contents." Subsequently, after trying out the DTTs for Malay Language and English, Celine commented that she could not pay attention to the lessons when using the DTTs, "I will lose my concentration because all I need to do is just listen to the contents. I will need to do nothing else. My mind will go everywhere." She elaborated more, "Honestly, I think in learning...we have to read from a book...that would be a more effective way of learning." She preferred Braille textbooks compared to the DTTs as she stated, "I think...I will not use the books. I prefer and am comfortable to read the contents from Braille textbooks."

\section{Difficulty of the Innovation}

Another theme that emerged from the data derived from the students' perception was the difficulty to access the DTTs, which refers to the complexity of the DTTs to be used by a 
student. Students provided feedback that the DTTs were quite difficult to be used because of several shortcomings. Due to these identified shortcomings, these students rejected to use DTTs. For some students, using the DTTs were not feasible, as Basyirah commented, "Technically the digital talking textbooks are not that feasible, as we cannot simply rewind the CD to the section that we wanted to go." She further elaborated, "The digital talking textbooks are not user-friendly at all. The voices will keep reading the contents out loud. We cannot even pause and rewind to the contents that we would want to go back."

The other students experienced misgivings about the voices chosen to deliver the contents in the DTTs. In describing his experience, Hong stated, "Sometimes...I do not understand what the voices were trying to convey. The pronunciations are not that clear." Zaiful also echoed his same experience as, "The voices pronounced every word one by one...it is a pain in the butt to keep listening to that." Celine expressed the ineffectiveness of the DTTs in terms of understanding the learning outcomes, "To answer the topical exercises from the digital talking textbooks...we have to 'stop' the device and answer the questions...for me that is not feasible at all." She further emphasized:

I do not think the digital talking textbooks are helpful enough. It is a little bit difficult because I do use the Brailler a lot; it will take longer time to execute any tasks when I use the computer and we do pause a lot...therefore, the reactions will get slower...and that is really time consuming for me.

Another student, Enn, perceived that the DTTs for both Malay Language and English did not help in learning the subjects. As a result, Enn preferred Braille textbooks:

The digital talking textbooks do not really help as much as the Braille textbooks do. For example, whenever we try to figure out the answers for the topical exercises given, we ought to understand the questions and reread the questions many times. I think the Braille textbooks will help find the answers more quickly in that sense. 
Enn further claimed that she found the DTTs' content for both subjects were not well organized. Subsequently, she suggested, "The chapters included in the DTTs should be more organized...so that it will be more feasible to be used."

Likewise, Zaiful remarked that accessing the content of the subjects on DTTs was quite complicated, "It is a little more difficult to use the digital talking textbooks [for topical exercises]...because we need to fast-forward and rewind to figure out the answers for the questions, it is way more difficult to search for the answers." Daniel was also concerned about the difficulty of accessing the contents of the DTTs, "Contents-wise, some chapters are too long to be true. It is very difficult for me to identify the important points for the chapters." He extended his feedback:

The learning objectives...should be conveyed in a simpler way. Another example is from the Islamic Education; the voice read aloud the Quran verses 1 through 49 continuously. I do not think that chapter needs the voice to read the entire verses 1 through 49.

Mirul also commented on the difficulty of using the DTTs, "Whenever we start to read the contents, we cannot stop the voices. Therefore, when we decided to stop...we have to start all over again at the time when we would like to resume listening to the contents."

\section{Usefulness of the Innovation}

Another characteristic of the innovation affecting the adoption of the DTTs is the usefulness to the students. This emergent theme refers to the helpfulness of the DTTs for students to assist learning. Adoption occurred when the students believed that the DTTs could help them learn, understand better, and apply the information in the group discussions. According to Naim, the DTTs were useful learning materials for group discussion, "The digital talking textbooks really help us to comprehend and be prepared for the group discussions." $\mathrm{He}$ said that the innovation helped students in preparing for class, "We do not have to wait for the 
teachers to introduce the subject matters; however, we could go ahead and listen, and we certainly could comprehend the contents."

Zaiful and Teh both recognized the usefulness of the DTTs in learning. They adopted the DTTs for Islamic Education and they both contended that the innovation helped them to understand the lessons. Zaiful reported, "I may not get right away the contents that the teachers are discussing about...therefore, the digital talking textbooks could help.” Teh shared her experience, "[The digital talking textbooks] help me understand the contents that are also learned by the other students...from the regular textbooks that they use in school."

Although some students experienced challenging situations when using the DTTs, at some point, each admitted that the DTTs were helpful in assisting them with school tasks. As Hong declared, "It does help [homework]...even though sometimes it is a little difficult." Daniel commented that using the DTTs in finishing up his homework is time saving, "Time-wise, I can save a lot more time when I use the digital talking textbooks for other school activities [homework]."

\section{User-Friendliness}

User-friendliness is essential in persuading students to adopt the DTTs. Overall, the students acknowledged that the current DTTs are "portable," "handy," "feasible," "userfriendly," and "easy to be copied." Daniel, who started to use the DTTs a year ago, mentioned the DTTs were user-friendly. He pointed out, "Even though I do not use the DTTs as frequent as the Braille textbooks, the benefits of the DTTs would be...its user-friendliness." As a result, he planned to continuously adopt the digital talking textbooks to assist him with learning. He further reiterated, "I think from now on, I would want to use it because it is easy, handy, and more feasible to share and discuss the knowledge with my peers." 
Another student admitted that the DTTs are portable, which means the DTTs could be used anytime and anywhere. Hong, who has basic skills in computing, stated, "The digital talking textbooks are more portable as compared to the regular textbooks [Braille textbooks]. The regular textbooks are bigger, thicker, and heavier." From his experience with the DTTs, he planned to keep using the innovation in the future. He said, "I will try to keep using it but I am not that familiar with the digital talking textbooks yet. I just used it last week so I may need some time to really master it."

Zaiful and Mirul, who both had experience using the DTTs for History and Islamic Education, acknowledged the portability of the DTTs. Zaiful pointed out, "During the free time, we certainly could listen to the contents of the subjects from the DTTs; it is also lightweight, handy, and portable." On the other hand, Mirul said, "It is super easy too...can be used anywhere...with the digital talking textbooks, we just need to switch on the computer, find the pages that the teachers would want us to focus, and we just browse through the pages needed." Another student, Naim shared:

We could listen to the contents almost anywhere and we could copy it into MP3 files too...I usually use the digital talking textbooks while in the classroom as well as at the dormitory. I do have copies of the digital textbooks' contents in MP3 files. We can save everything in a pen drive, and we could listen to it anywhere at our own convenience.

\section{Super-Ordinate Theme 2: Support to Use the Innovation}

The second super-ordinate theme that emerged from the data was support to use the DTTs from teachers, parents, peers, as well as self-driven behavior. This super-ordinate theme refers to any encouragement or motivation that stimulates students to adopt the DTTs. Figure 3 shows the coding network for this super-ordinate theme. The four emergent themes (a) peers'

support, (b) teachers' support, (c) self-driven behavior, and (d) parents' support, are represented around the super-ordinate theme. 


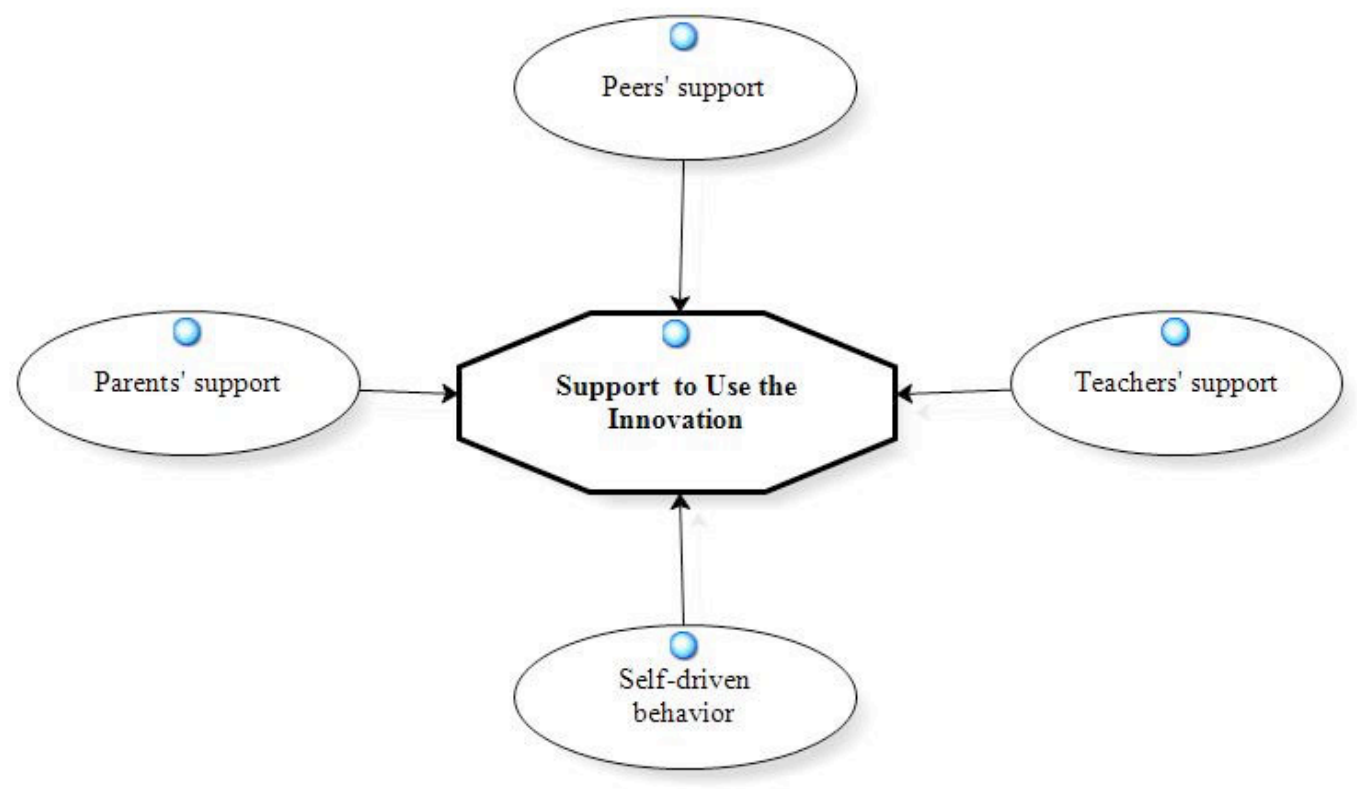

Figure 3. Coding network for super-ordinate theme 2, support to use the innovation.

\section{Peers' Support}

Students also reported that they received support from friends on how to use the DTTs. Enn, who used FSReader ${ }^{\mathrm{TM}}$ with help from his friend, pointed out, "A friend has introduced me to the software [FSReader ${ }^{\mathrm{TM}}$ ]. I am not that skillful in computer technology; therefore, I requested that friend to install the software into my computer." He added, "My friends encouraged me to use it. I listen to the digital talking textbooks with them...they said it is a great way of learning. We could listen to the textbooks, gain the knowledge, and discuss the contents together."

Another student shared her amazing experience of learning together by demonstrating how to use the innovation to her friends, Teh said, "I do explain to them [friends] about the benefits of the digital talking textbooks...only certain things that I know." Meanwhile, Daniel admitted that his friends showed and shared the skills in using the innovation, "Other than that, my peers are being so supportive about the digital talking textbooks...they [peers] show me a lot about how to use the digital talking textbooks more efficiently." 


\section{Teachers' Support}

Another theme emerged from the data derived from students' observations of teachers' support in using the DTTs. Most students received support about the subject from teachers. For instance, Naim received encouragement to keep using the innovation from History and Islamic Education teachers, "They really encourage us to use the digital talking textbooks because it is very practical." He added, "They provided us with the digital talking textbooks, computers, and manual." Aziz reported that he received help from his teacher to use the innovation due to unavailability of the other learning materials for the particular subject, "My Islamic Education teacher helps me in using the digital talking textbooks...because there is no Braille textbooks available for Islamic Education.”

Most students received support from teachers in terms of receiving permission to use their own laptops during school hours. Moreover, the teachers also demonstrated to these students how to use the DTTs. Zaiful said, "The teachers are all really helpful in terms of granting the permission to bring our own laptops." Ning also said that the teachers encouraged them to use the DTTs, "The teacher demonstrated to my other peers, and one of my peers showed me how to use the digital talking textbook."

\section{Self-Driven Behavior}

In addition to support from teachers, parents, and peers, the students' interest in using the DTTs comes from within, which forms the theme of self-driven behavior. According to Mirul, "I have my own interest too, to use the digital talking textbooks...I explore everything by myself...it is super easy." Teh said that most of the time she explored the DTTs by herself and received help from friends. She proudly shared that she was also able to access the DTTs out of her own curiosity as, "Umhh...I did explore everything by myself and asked my peers around." 
Another student, Naim, was exposed to the innovation two years ago, realized that there were many advantages to utilizing this innovation for students. Among the advantages he identified were mostly related to the innovation's user-friendliness characteristic such as its portability. For this academic year, he requested the DTTs for History and Islamic Education from the teachers, "I requested the digital talking textbooks from my teachers, and I easily could listen to its contents." Meanwhile, Enn viewed that the advantages of the DTTs may encourage the students to get to know and adopt the innovation. She summarized her opinion by saying, "Personally, the digital talking textbooks are one new assistive learning tool that many students will get attracted to its benefits."

\section{Parents' Support}

Students reported that they received support from their parents to use the DTTs. One student, Naim, who occasionally used the innovation at home during weekends, said, "I use it sometimes at home...and they [parents] also encourage me to use it...They [parents] are absolutely okay with the digital talking textbooks, mainly because it serves its purposes well." Hong, who used a DAISY player, a portable player to access the contents of the DTTs, acknowledged that his parents strongly motivated him to use the innovation, "I own it [DAISY player] at home. My parents bought it for me...they were amazed by the digital talking textbooks...and they said learning will be so much easier if I use the innovation."

\section{Super-Ordinate Theme 3: Knowledge of the Innovation}

This theme represents the students' knowledge of the DTTs, including their awareness of the purpose of the innovation, features of the innovation, sources of information, and familiarity with the innovation. Figure 4 shows the coding network for this super-ordinate theme. The octagon in the middle represents the super-ordinate theme, knowledge of the innovation. The 
four emergent themes: (a) knowing the purpose of the innovation, (b) familiarity with the innovation, (c) sources of information, and (d) awareness of features, are represented around the super-ordinate theme.

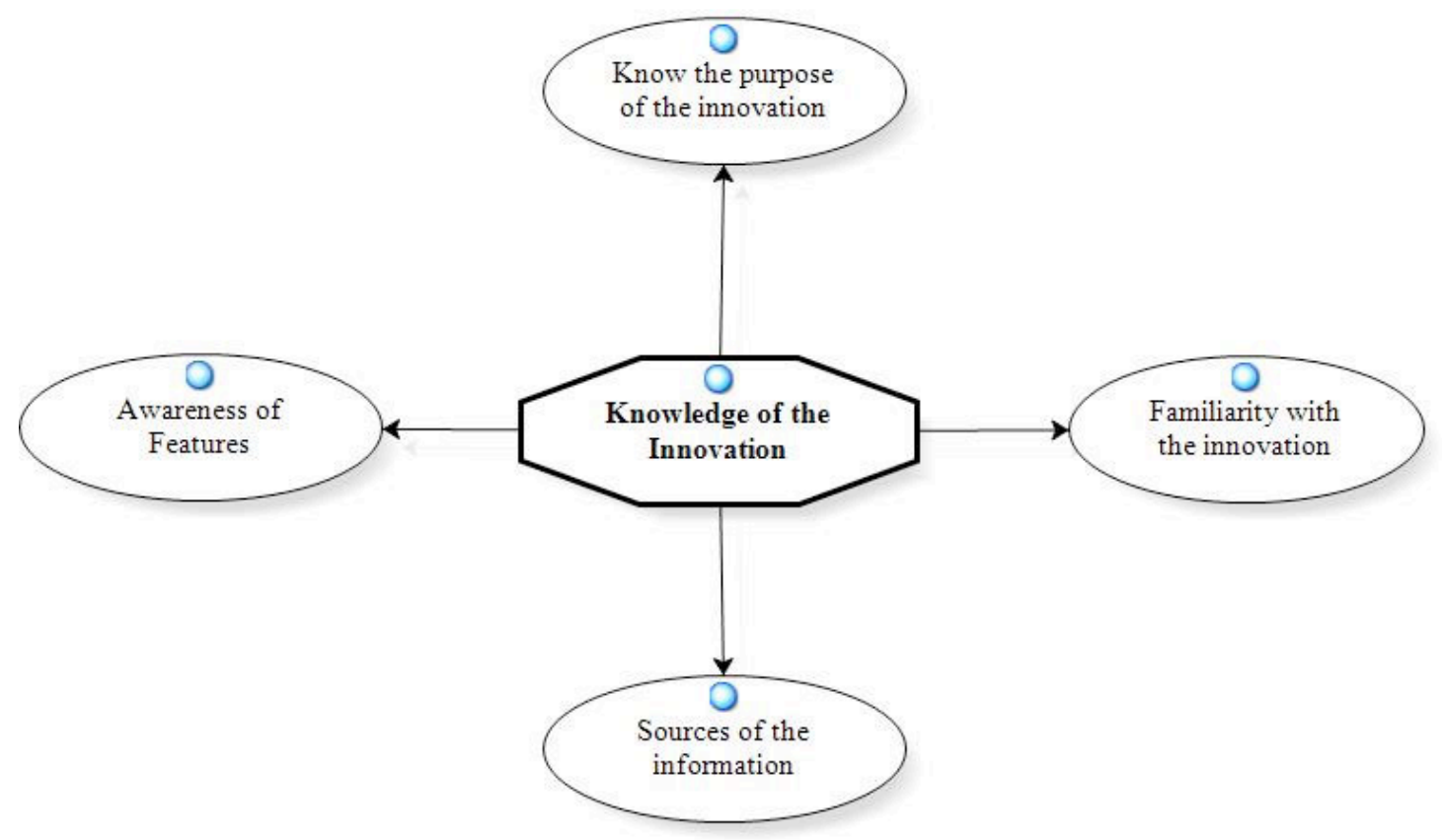

Figure 4. Coding network for super-ordinate theme 3, knowledge of the innovation.

\section{Know the Purpose of the Innovation}

One theme that emerged from the data was how concerned the students were with the purpose of the DTTs. Students strongly believed that the main purpose of the DTTs was to help students with learning. Daniel said, "[The digital talking textbooks] were provided by the Ministry for blind students to help us in learning." Daniel, Basyirah, and Naim realized the purpose of the innovation. Basyirah mentioned, "It was provided by the Ministry of Education for the blind students to be used in learning." Naim echoed, "The digital talking textbooks were provided by the Ministry of Education, Malaysia to be utilized by all students with visual impairments." Another student, Aziz, fully informed on the purpose of the DTTs, said, "Umhhh...it could help those who are illiterate or unable to read." 


\section{Familiarity with the Innovation}

Another factor identified by the students was the familiarity with the DTTs. Students discussed their familiarity with the DTTs in different ways. Ning, who received the DTTs for Malay Language, mentioned, "I am not getting used to it yet. I will see what I could do with that." She acknowledged, "The students are not really familiar with the digital talking textbooks yet." Another student stated that DTTs are new learning materials. Hong said, "I just used it last week so I may need some time to really master it." He stressed, "For those who do not understand really well the technical part of using the digital talking textbooks, they will easily get bored."

Meanwhile, Enn expressed, "I just knew and received the digital talking textbooks last Friday. My other peers received it a few days earlier than me...on Monday the same week." She added, "I am not sure about the digital talking textbooks because I am not fully master the usage of the digital talking textbooks yet." Basyirah, who depended on a desktop at the computer laboratory for accessing the DTTs, perceived that the computer skills were the main key to efficiently master the innovation, "Some of the students are not really skillful in using the computer...therefore, to get the $\mathrm{CD}$ functions correctly might be a new challenge for them...and it will be time consuming to learn all these new skills."

\section{Sources of the Information}

According to the students, the school's administrator and the teachers were the primary sources of information and knowledge about the DTTs. Several students learned about the innovation through the school's administrator, particularly the Senior Assistant of the Students' Affairs. Students reported that the Senior Assistant of the Students' Affairs informed and provided the DTTs to be explored and used by the students. As Celine pointed out, "I am just 
being informed about the digital talking textbooks. We received the $\mathrm{CD}$ of the digital talking textbooks last week from the Senior Assistant of the Students' Affair."

Another student who was exposed to the DTTs since she was in elementary (primary) school reported that the school administrator was the main source of information about the DTTs, Ning said, "From my teacher, the Senior Assistant of the Students' Affairs." Enn also knew about the DTTs from the school administrator, as she reported, "She had informed us about the digital talking textbooks are now available in school...she asked me to experience it."

A few students disclosed that they received the information about the DTTs from the teachers. For example, two students reported their Islamic Education teacher informed them about the innovation and provided the DTTs for their use. Mirul said, "My Islamic Education teacher told me about that." Similarly, Naim said, "My teacher told about it [digital talking textbooks]." Ruddin, who received the DTTs for Malay Language and English subjects two weeks prior to the interview, said, “A teacher provided me with the digital talking textbooks' CDs and I started to use it right away."

\section{Awareness of Features}

It is important to differentiate between DTTs and other learning materials such as the learning modules in CDs, which are provided by the other divisions under the Ministry of Education, specifically the Educational Technology Division and the Special Education Division. The content of modules contained mainly the selected topics from printed textbooks, and then transferred into audio CD with animation to help students understand the topics. The content of the CDs can be accessed by using media player, but is not compatible with the DAISY player and software. 
The Ministry of Education, through the Textbook Division, produced the DTTs specifically for students with visual impairments. Aziz confirmed, "It is a textbook in CD for students like me [visually impaired]." Zaiful confidently reported, "It [the digital talking textbooks] comes in CD and we could listen to the book with computer." Ruddin referred to the same innovation as, "It's a CD. We could listen to the lesson through computer." Similarly, Mirul mentioned, "The audio books...to help visually impaired students in their learning." He added, "The digital talking textbooks come with the CD...therefore, it is way so much easier to be copied."

\section{Super-Ordinate Theme 4: Challenges for Effective Use of the Innovation}

This super-ordinate theme represents the students' feedback on the challenges in using the DTTs. For this study, challenges are seen as limitations to effectively adopt the DTTs. Students identified three major challenges to use the DTTs, including: teachers' lack of trust, limitations of time, and unavailability of the devices to access the contents of the DTTs. Figure 5 shows the coding network for this super-ordinate theme. The octagon in the middle represents the super-ordinate theme, challenges for effective use of the innovation. The three emergent themes: (a) teachers' lack of trust, (b) unavailability of devices, and (c) time limitation, are represented around the super-ordinate theme. 


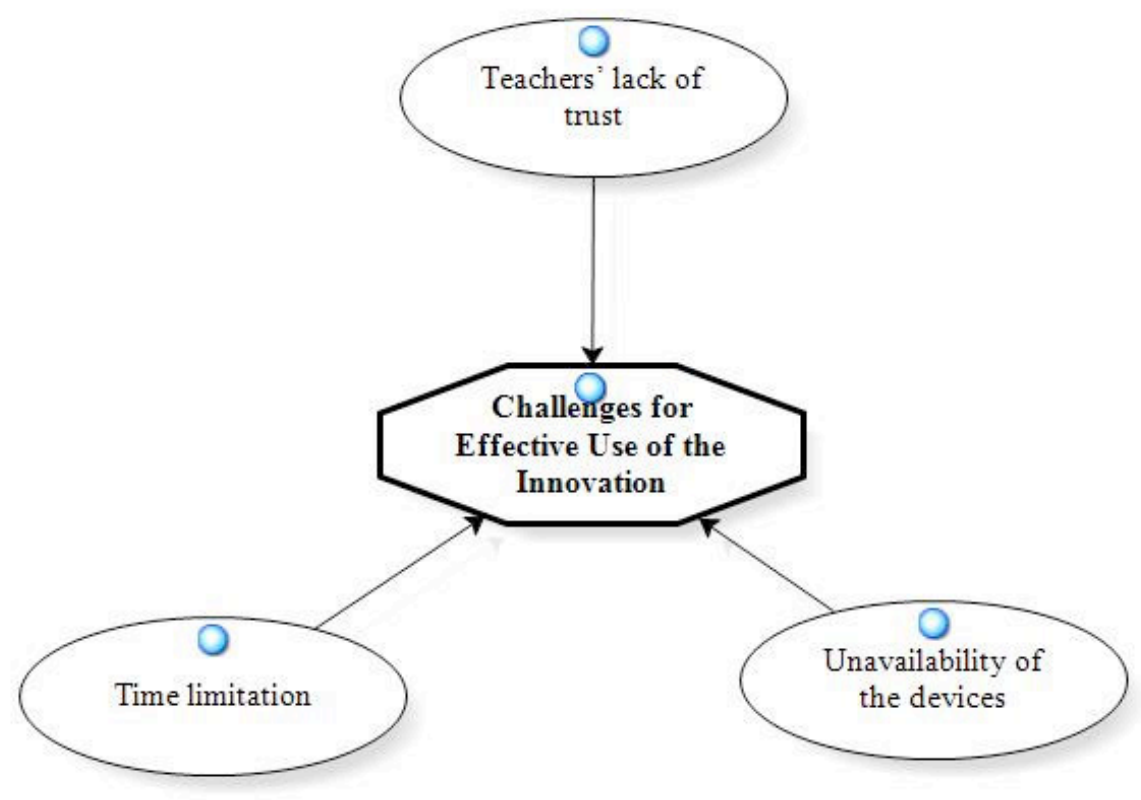

Figure 5. Coding network for super-ordinate theme 4, challenges for effective use of the innovation.

\section{Teachers' Lack of Trust}

Lack of trust from the teachers to the students who were using the DTTs during the school hours was another emergent theme. The example of lack of trust described by one student was suspicion. The suspicion was derived from the teachers' past experiences with certain students such as, instead of listening to the content of the syllabus, students are listening to the music. Mirul shared, "The teachers sometimes get suspicious with us...we might actually listen to the music, not to the contents of the syllabus."

\section{Unavailability of Devices}

The unavailability of devices such as personal computers and players affected students' use of the DTTs. Although several students received the DTTs, they encountered unavailability of devices to access the content of the books. The students agreed that the absence of the device affected the adoption of the content to the DTTs. As Ruddin commented, "For those who do not own personal computers, that might be a challenge...they cannot use the digital talking textbooks 
then." Hong claimed, "For students who do not own laptops or the DAISY players, they will not be able to use the digital talking textbooks."

Basyirah, who did not own a personal computer, expressed, "If there will be homework for certain chapters, we need to have a computer to execute the tasks given. Not every student has a computer as I have not. It is not very feasible for me." Similarly, Enn experienced the absence of a device when she wanted to use the DTTs, "Whenever I wanted to use the digital talking textbooks, I do not have a computer available. If I have limited time to execute certain tasks, I would use the Braille textbooks. It is a lot quicker and more feasible." As a result, she preferred to use the Braille textbooks rather than the DTTs.

Daniel explained, "Its just that some of them do not own computers...these students might face a little difficulty accessing the digital talking textbooks." Celine said, "Say for example a student chooses to use the digital talking textbooks, and that particular student does not own a computer...that might be a huge problem."

\section{Time Limitation}

Another challenge to effectively use the DTTs as described by the students is the limitation of time. Several students noted that school activities, particularly co-curricular such as school clubs and sports activities, were among the main reasons they refrained from using the DTTs. For instance, Enn disclosed, "I had quite a lot of homework to finish up, so I did not have space to use the digital talking textbooks." Similarly, Celine said, "I usually use it at home

because the schedules while I am at school are so tight." Basyirah also said, "As I explained earlier, not every student owns a computer. When we do have homework, we will be able to do it in the evening since we will usually have extra co-curricular activities in the afternoon." 
In addition to the tight schedules and amount of activities designed for that particular school, the students experienced limitations of time to use the computer laboratory facilities. Zaiful said, "The computer laboratory at school is operated within its limited time schedule." Another student, Basyirah, discussed the challenge she faced regarding the computer laboratory, which usually operated within a limited time schedule. She expressed her dissatisfaction by saying, "The computer laboratory will be opened just in the afternoon...so, it is difficult to get your homework done using the computer and the CD provided."

\section{Super-Ordinate Theme 5: Alternatives to the Innovation}

This super-ordinate theme addresses the students' alternatives to the DTTs. Instead of solely using the DTTs, students reported they used multiple learning resources, including printed Braille textbooks, Closed Circuit Televisions (CCTV), personal readers, Internet, as well as notes and materials from their teachers. These multiple learning resources were all available at the school except for personal readers. Personal readers were only available for students based on parents' choice at their own cost. Figure 6 shows the coding network for this super-ordinate theme. The octagon in the middle represents the super-ordinate theme, alternative to the innovation. The five emergent themes, (a) teacher's notes and materials, (b) Internet, (c) personal readers, (d) close circuit television, and (e) printed Braille textbooks, are represented around the super-ordinate theme. 


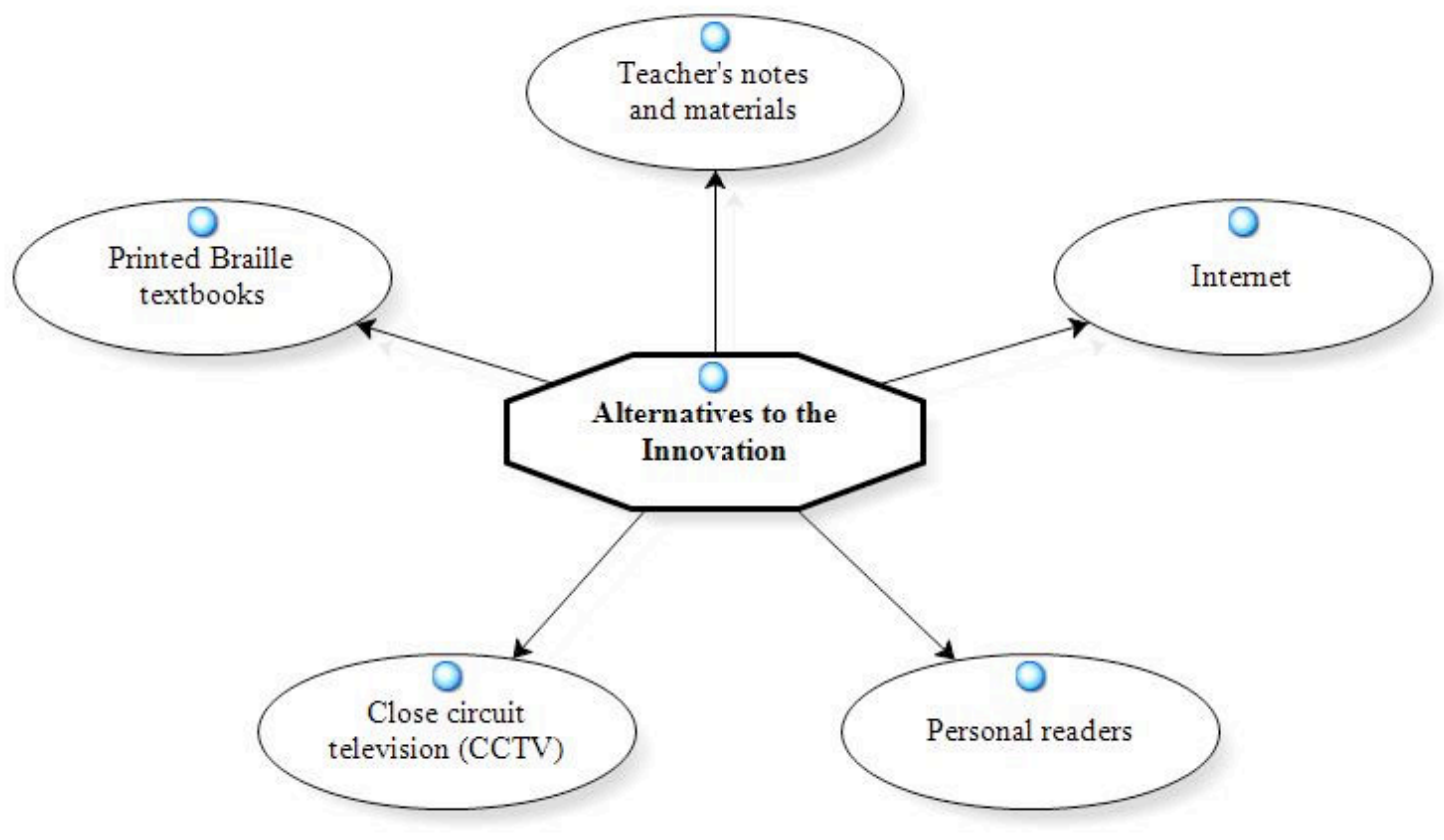

Figure 6. Coding network for super-ordinate theme 5, alternatives to the innovation.

\section{Teachers' Notes and Materials}

One alternative to the DTTs was teachers' supplemental notes. Basyirah stated, "I use the Brailler. The teachers also provided the notes in the soft copy." Another student thought one effective way of learning would be to review teachers' notes as well as additional reading materials supplied. Celine said, "The notes would be in the Braille form. I use the Brailler a lot. The teacher will read the contents out loud and we would jot down the notes. That is an effective way of learning I guess."

\section{Internet}

Some students viewed the Internet as a valuable learning resource and succinctly described the importance of the Internet in their learning process. Mirul pointed out, "I also use the Internet and the revision books." Subsequently, Naim provided his experience, "I usually browse the Internet. It helps a lot to find all sort of information.” Another student, who also used the DTTs for Islamic Education, browsed through the Internet to find the additional 
notes and support materials for the subject, Teh said, "Additional notes [for Islamic Education]

from the Internet." Other than using the DTTs, Daniel also chose to use the Braille textbooks and browse the Internet. He mentioned, "Sometimes, I do browse the Internet to search for information."

\section{Personal Readers}

Another alternative to the DTTs preferred by students are personal readers. The task expectation for a personal reader is to read the contents of the subjects to the students. Unique to Naim and Enn, they requested their friends to be their personal readers and to read the regular textbooks to them. Naim said, "I also use the reader or ask others to read aloud for me, usually my peers." Enn employed a personal reader for the specific subjects without the digital talking textbooks or Braille textbooks. She pointed out, "There are certain subjects that do not have the Braille textbooks available such as the Living Skills; therefore, we may need to ask peers to read out loud for us from the Braille textbooks." Celine usually asked her parents to read the printed textbooks. She said, "My parents would assist me with that matter...they will read the contents out loud for me...and I will do chapter revisions together with them."

\section{Closed Circuit Television (CCTV)}

One of the assistive technologies that helped the students with visual impairments, especially low vision students, was CCTV. Ning shared her experience, "I use CCTV to read the regular textbooks." She only opted to use the DTTs when the CCTV was not available, such as when she was in a dormitory, "Sometimes I could not get the CCTV in my dormitory. Therefore, the digital talking textbooks might help me access the contents of the syllabus." Another student, who was comfortable with the DTTs, also used the CCTV as a learning tool. Naim said, "I also use the CCTV to read the regular textbooks." 


\section{Printed Braille Textbooks}

Printed Braille textbooks have long been recognized as the main learning resource for students with visual impairments. Instead of using the DTTs, many students preferred to use the Braille textbooks. Aziz declared, "I use the Braille textbooks a lot," and added, "I think the Braille textbooks are more helpful than the digital talking textbooks." Daniel said the same, "I typically use Braille textbooks and Brailler [braillewriter]." Basyirah said that she was more comfortable using the Braille textbooks compared to the DTTs, "I am more comfortable with the Braille textbooks thus far." Her preference was supported by Celine, "I think...I will not use the books [the digital talking textbooks]. I prefer to read the contents from Braille textbooks," Celine added, "I think...it will be more time effective if I flip through the pages from the Braille textbook."

\section{Super-Ordinate Theme 6: Adaptation to the Innovation}

The adaptation to the DTTs among the students is the last super-ordinate theme. The adaptation occurred when students took initiatives in using the DTTs, based on financial affordability, to own certain devices such as external speakers and MP3 players. Figure 7 shows the coding network for this super-ordinate theme. The octagon in the middle represents the super-ordinate theme. The two emergent themes (a) the use of MP3 players, and (b) the use of portable external speakers, are represented around the super-ordinate theme as the types of the adaptation in adoption of the DTTs. 


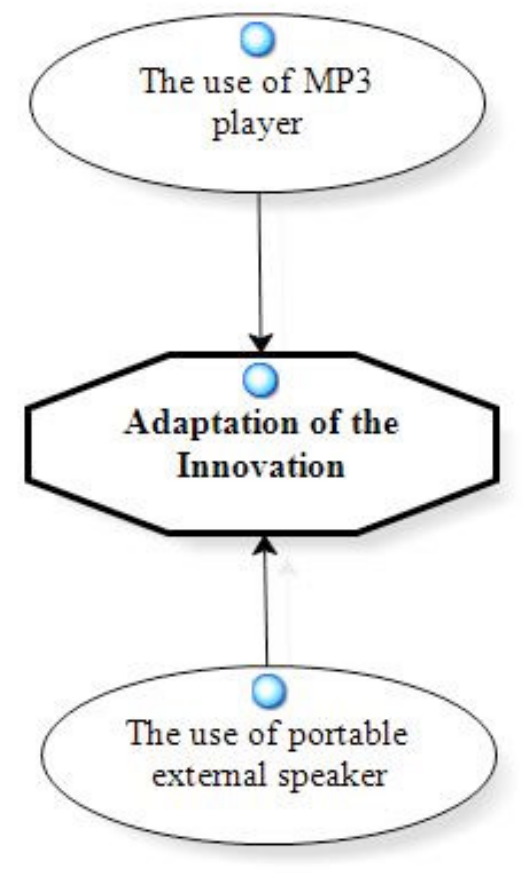

Figure 7. Coding network for super-ordinate theme 6, adaptation of the innovation.

\section{Use of MP3 Player}

As for alternative options to the computer and portable reader, Teh and Naim individually employed an MP3 player to listen to the content of the DTTs. Teh stated, "The CD can be burnt, and I could listen to the content by using the MP3 player." Naim added, "I do have copies of the digital talking textbooks' contents in mp3 files. We can save everything in a pen drive, and we could listen to it anywhere at our own convenience."

\section{Use of Portable External Speakers}

The portable external speaker, which most participants bought from the school's bookstore, is one alternative device for listening to the digital talking textbooks' content. Daniel said:

The external speaker that could be used the thumb drive, simultaneously. We could buy it from the school cooperation shop. We could transfer the digital talking textbooks' files into the thumb drive, and then access the contents of the digital talking textbooks through the external speaker. 
Similarly, Mirul transferred the contents of the digital talking textbooks into a thumb drive and listened to the contents using an external speaker, he mentioned, "We could save the learning contents into a thumb drive and use a small speaker to listen to the contents." Another participant also recognized the benefit of using the external speaker as Enn shared:

If we opt for the speaker, those who cannot afford to buy computers will also be able to listen to the contents. I think both are feasible; however, to be able to share the contents with more people...the speaker and the MP3 files will serve the purpose well.

She further emphasized, "We could listen to the digital talking textbooks through the speaker without using the computer."

\section{Chapter Conclusion}

This chapter presented six super-ordinate themes and 23 emergent themes revealed by the students. The themes were identified through an iterative data analyzing process, as followed from the IPA research procedures. The super-ordinate themes were (1) functionality of the innovation, (2) encouragement and motivation to use the innovation, (3) knowledge of the innovation, (4) challenges for effective use of the innovation, (5) alternative to the innovation, and (6) adaptation to the innovation. The researcher believes these provide the reader an avenue for in-depth understanding on the experiences of students with visual impairments using the DTTs to assist learning. 


\section{CHAPTER 5: INTERPRETATION AND DISCUSSION}

To understand the phenomenon under investigation, the researcher interviewed twelve students with visual impairments in a school for students with visual impairments in Malaysia. The students' experiences in using the DTTs differed widely, but six super-ordinate themes were derived from the interview transcripts: (1) functionality of the innovation, (2) encouragement and motivation to use the innovation, (3) knowledge of the innovation, (4) challenges for effective use of the innovation, (5) alternatives to the innovation, and (6) adaptation of the innovation.

As suggested by Willig (2008) and Smith (2004), this chapter elaborates on the six superordinate themes, relating them to the literature and the model of innovation previously discussed. The discussion of the six super-ordinate themes is framed around the concept of 'adoption' and 'rejection', as well as 'discontinuance' as broadly discussed in the Diffusion of Innovations Model (Rogers, 2003). For this study, adoption of the innovation occurs when students formed positive attitudes toward DTTs and decided to use the innovation.

Rejection of the innovation occurs when students experienced shortcomings of the DTTs. Rogers (2003) describes two types of rejection: (a) active rejection, which occurs when students consider adopting DTTs after a trial period, but then decide not to use the innovation; and (b) passive rejection, which occurs when students do not consider using DTTs. Discontinuance occurs when students make a decision not to use DTTs after previously adopting them, as a result of dissatisfaction with the performance of DTTs. The students then choose to use other learning resources, which may replace the DTTs.

This chapter will have a discussion of the implications of the findings, followed by revisiting the researcher's assumptions prior to initiating this study, research limitations, 
recommendations for research, researcher's reflections based on experiences when conducting this study, and the research conclusion.

\section{Functionality of the Innovation}

Functionality of the innovation refers to the characteristics of DTTs, including: usability, comfortableness, difficulty, usefulness, and user-friendliness. The researcher recognized the students with visual impairments' interest in using DTTs for learning was partly the result of these characteristics. Although students shared different experiences in using DTTs, they acknowledged the characteristics of DTTs that affected their enthusiasm, or lack thereof, about DTTs.

Some students described experiencing technical difficulties when using DTTs, such as: "cannot simply rewind the CD to the section that we wanted to go," "have to stop the device to answer the topical exercise," "it will take longer time to execute the tasks," and "difficult to search for the answers." These problems discouraged the use of DTTs. This finding is consistent with a study by Holcombe (2000), who concluded that an innovation with less complexity has a higher possibility of being adopted than an innovation with complicated features. Rogers (2003) suggested that although the complexity may not be as important as the other attributes of the innovation, such as relative advantage or compatibility, it is an important barrier to adoption and may influence its implementation and rate of adoption.

Findings from the current study also support the Diffusion of Innovation Model (DOI) that addresses the attributes of innovation, in relation to the adoption of innovation. Again, Rogers' attributes of innovation included: relative advantage, compatibility, complexity, trialability, and observability. Usability and difficulty were two characteristics of DTTs that emerged from the data that are congruent with Rogers' attributes of innovation, particularly, 
compatibility and complexity. Students viewed the usability of DTTs as influencing their interest in adopting the innovation. These students used DTTs with existing available applications such as Windows media player, hardware players such as the DAISY reader, and portable speakers.

The usability of DTTs for selected subjects also could determine the decision to adopt or reject the innovation. For instance, several students declared that DTTs were not suitable for English and Malay Language. Consequently, they stopped using the DTTs designed for these subjects after an initial use. Based on the researcher's professional experience teaching the Malay Language, the negative experience with the DTT was perhaps due to the nature of language as a subject itself. Learning any language is more focused toward comprehension and composition skills. To acquire these important skills, students are required to comprehend the contents and apply it through writing exercises. The DTTs may let students listen to and help them understand the language; however, students may not be able to readily apply what they hear in writing and composition exercises.

Rogers (2003) mentioned that compatibility of an innovation consisted of three components that may lead to adoption: (a) previously introduced idea, (b) users' need, and (c) values and belief. Baker and Bellordre (2004) reported incompatibilities of an innovation with users' purposes could generate barriers to the efficient and effective use of innovation or technology devices by users with disabilities, and may persuade them to reject the innovation.

Another important characteristic of DTTs that emerged was user-friendliness. This characteristic refers to the flexibility, portability, ease of use, and accessibility of the innovation. Students indicated that DTTs are user-friendly compared to Braille textbooks by being "handy," "portable," and "can be copied." Students consistently reported adopting the DTTs due to user- 
friendliness features, which is consistent with previous studies on the importance of an innovation characteristics and innovation effectiveness. Buabeng-Andoh (2012) said that the effective and successful use of innovation depends on the accessibility of the innovation. Different studies found other characteristics of the innovation associated with increased use of innovation: ease of use and effectiveness (Batavia \& Hammer, 1989; Yaeda \& Rubin, 1992); efficiency and comfortableness (Brooks \& Hoyer, 1989); safety (Mallik \& Elder, 1993); and performance (Scherer \& Galvin, 1996).

Another characteristic of innovation that may influence the adoption of DTTs is the direct benefit to students. This emergent theme is identical to the relative advantage in the DOI. According to Rogers (2003), the relative advantage can be measured by time savings, decreased discomfort, economic productivity, social status, and immediacy of reward. Students reported experiencing many benefits of DTTs, such as assisting with school tasks, preparing for class and group discussion, and comprehending the lessons. These direct benefits stimulate students to adopt DTTs because the innovation can save time in executing their homework and help them understand the content. The findings are consistent with studies that addressed the benefits of an innovation influencing adoption of the innovation (Cooper \& Nichols, 2007; Howell, 1996; Huang \& Russell, 2006; Kapperman, Sticken, \& Heinze, 2002; Kennedy, 2002; Merbler, Azar, \& Ulman, 1999; Strobel, Fossa, Arthanat, \& Brace, 2006; Trucano, 2005).

\section{Functionality of the Innovation: Adoption and Learning}

This study found that adoption to an innovation could occur among students with visual impairments when the innovation has characteristics of usability, comfortableness, usefulness, and user-friendliness. These characteristics enhance functionality of the innovation to foster and 
assist learning. When students adopt DTTs, they could easily access lessons and chapters, comprehend, and execute the tasks and homework to deepen their understanding for the subjects.

\section{Support to Use the Innovation}

Support from government, community, parents, and peers are important factors to the successful use of an innovation. Studies identified that the school community and school facilities are necessary for successful use of innovation among students with visual impairments (Apling \& Jones, 2007; Edyburn, 2004; Kelly, 2009; Poel, 2007). Scholars have recognized the critical role of teachers in supporting students using innovation and assistive technology (Lahm \& Nickels, 1999; McGregor \& Pachuski, 1996; Silberman \& Sacks, 2007).

The current study found the school administration, particularly the assistant principal and teachers, encouraged students to use DTTs. It was described as "granting permission," "teacher encouraged me,"” and "teacher demonstrated." According to Beigel (2000), students who do not receive support from teachers and school administrators are unlikely to adopt an innovation, and may abandon the devices. In facilitating students to use the innovation, this researcher suggests that teachers demonstrate the use of DTTs, as requested by a student who said, "Teacher should demonstrate." Rogers (2003) addressed that in the innovation-decision process, support from change agents, such as teachers, is effective in stimulating adoption of an innovation and speeding up the diffusion process. Sharpe (2010) found support from professionals, including teachers, is paramount in implementing an innovation in education settings for students.

The other important factor that affects students' adoption of an innovation is their own personal characteristics, including patience, self-motivation, personal priorities, self-confidence, expectations, and acceptance of their disability (Goodman, Tiene, \& Luft, 2002). This finding is consistent with the findings from studies when some students reported they adopted the DTTs 
due to their self-driven behavior. The researcher believes that students' self-motivation in using DTTs comes from the awareness and knowledge of the benefits of the innovation, which is in accordance with their interests, needs, and existing attitudes as described by Rogers (2003).

\section{Support to Use the Innovation: Adoption and Learning}

This study found that support from school administrators, teachers, parents, and peers to use the DTTs encouraged students to adopt the innovation. Support from these change agents is effective in stimulating diffusion of DTTs and speeding the adoption process among students with visual impairments. For instance, parents who are supportive by providing DAISY players to their children could stimulate adoption. By owning DAISY players, the children could make full use of DTTs and help them to learn any lesson in a more effective way than conventional printed learning materials such as Braille textbooks. For example, by using DAISY players, students could browse the content of the DTTs faster and could bookmark the desired pages or chapters feasibly.

\section{Knowledge of the Innovation}

Adoption or rejection of an innovation among students is dependent on their level of knowledge about the innovation. The significance of knowledge to the adoption of an innovation has been widely discussed. For instance, scholars relate knowledge and skills to the successful implementation of the innovation in teaching and learning (Benson \& Palaskas, 2006;

Dhanarajan, 2001; Ebersole \& Vorndam, 2003). Lack of knowledge (DeJonge \& Rodger, 2006), familiarity, skills, and training in using an innovation may cause rejection and abandonment of the innovation among students (Brokop \& McIntosh, 2009; Derer, Polsgrove, \& Rieth, 1996; Kapperman, Sticken, \& Heinze, 2002). 
In the innovation-decision process model, Rogers (2003) classified knowledge about an innovation into three types: (a) awareness-knowledge, (b) how-to knowledge, and (c) principlesknowledge. In this study, the researcher found that the students have the awareness-knowledge; which means, they are aware about the existence and benefits of DTTs. According to students' feedback, due to a lack of demonstrations on how to use DTTs from teachers, students lacked knowledge on how to use DTTs correctly and how to use their features efficiently.

Findings of the current study indicate that students were aware of DTTs and their characteristics illustrated as "the audio books," and "we could listen to the books with computer." They realized the main purpose of DTTs is to assist learning. However, the researcher found that these students did not have sufficient skills to use DTTs due to a lack of familiarity. The lack of familiarity may be due to the short-term period of usage. In this context, the researcher interviewed the students not long after they received the DTTs from their teachers.

The lack of familiarity with the innovation may cause the development of skeptical feelings concerning the effectiveness of the innovation (Baker \& Bellordre, 2004). Rogers (2003) stated that it is important for teachers to disseminate information on correct methods of using an innovation to avoid rejection of an innovation. This is supported by the students' reporting that the primary source of knowledge on DTTs was essentially derived from the assistant principal of the school, as described by students: "she told me about the books," and "I gained information about it from my teacher."

From the researcher's perspective, adoption of DTTs among students is based upon their knowledge, skills, and exposure to the innovation. Therefore, the change agents such as teachers, school administrators, publishers, as well as the Ministry, have to play crucial roles to 
deliver the benefits of DTTs and demonstrate effective uses of DTTs to foster adoption among students with visual impairments.

\section{Knowledge of the Innovation: Adoption and Learning}

Information about DTTs including the awareness and understanding on how to operate the innovation are crucial factors to adoption. In this study, students who received the information about the innovation from their teachers and school administrators adopted the DTTs to access lessons. These students claimed that their learning was more feasible than before they adopted the DTTs. Based on this situation, it is demonstrated that the Ministry's aim to help students with visual impairments learn better is achievable through the adoption of DTTs.

\section{Challenges for Effective Use of the Innovation}

In most educational settings, limitations to successfully use an innovation occur at many levels including classroom and student (Alper \& Raharinirina, 2006). One unexpected challenge experienced by students while using DTTs in their classrooms was teachers' lack of trust. Some teachers apparently had suspicion that students were not listening to the DTTs but were maybe listening to something else, one student said, "teachers sometimes get suspicious with us." From the information conveyed by the students, the researcher assumes that teachers who have lack of trust toward students who use DTTs were a result of teachers' past experiences with certain students; when the teachers actually trusted the students to use the DTTs to assist their learning, some students were caught to misuse the innovation by these teachers.

According to Fraser and Maguvhe (2008), lack of trust among teachers come from their lack of confidence to incorporate an innovation in teaching students with visual impairments. The current study is consistent with studies that reported teachers' pessimistic attitudes toward innovation. Teachers' pessimistic attitudes toward innovation were recognized as one of the 
challenging factors for students with visual impairments to effectively use the innovation (Cook \& Hussey, 2002; Copley \& Zivani, 2004; Fraser \& Maguvhe, 2008; Messinger-Willman \& Marino, 2010).

Another limitation to successfully adopt the DTTs, as experienced by students with visual impairments, is time. Sufficient time is essential for students to explore and use the DTTs. Scholars recognized that insufficient time to use an innovation or technology tool is a barrier to effectively adopting the innovation in education settings (Copley \& Zivani, 2004; Ebersole \& Vorndam, 2003; Messinger-Willman \& Marino, 2010; Owens, Leung, Lamb, Smith, Shaw, \& Hauff, 1999; Pajo \& Wallace, 2001).

Based on the interviews with these students, the researcher understands they do not have sufficient time allocated to use DTTs in the classrooms and in the dormitory, or at home due to school activities and limited time allocated in the computer laboratory. Although all students were provided with DTTs, not every student had devices or personal computers to access the innovation in the classroom. Thus, the computer laboratory was the only place for them to access the DTTs. Based on the computer laboratory schedules provided by the school administrator, the laboratory was available during school hours; and students had to participate in after school activities as part of the requirement of the school system. Therefore, they do not functionally have access to the lab for use.

Students reported that the unavailability of devices to access the contents of DTTs was a barrier to effectively use the innovation. For those who do not have personal computers, playback software, and hardware players, there was a high probability of rejecting the DTTs. Cook and Hussey (2002) classified the types of barriers as: (a) opportunity barriers, which include policy, practice, attitude, knowledge, and skill; and (b) access barriers, which consist of 
users' ability and attitude, unavailability of resources or devices, and lack of a support system.

Therefore, it appears access barriers were the primary challenges experienced by the students to adopt the DTTs.

\section{Challenges for Effective Use of the Innovation: Adoption and Learning}

Students shared challenges that they had while using the DTTs in the interviews.

Teachers' lack of trust, time limitations to adopt the DTTs, and unavailability of appropriate equipment limited the students' adoption of DTTs. These challenges are barriers to learning among students with visual impairments. Teachers' trust of students about what and how they learn is an important factor for students to succeed. For students, learning experiences could become more meaningful with trust given by the teachers. Extended facility hours at the computer laboratory and availability of appropriate equipment, such as the DAISY reader, could allow more opportunity for students with visual impairments to adopt DTTs. With more opportunities provided, these students could learn better by using the innovation to the fullest.

\section{Alternatives to the Innovation}

Students have various reasons to adopt this innovation, depending on the degree of blindness and perceptions of what innovation might be the most efficient for assisting their learning. There are many types of assistive technologies regularly used by students with visual impairments to assist their learning including: talking books, talking calculators, talking dictionaries, screen magnifiers, closed circuit television (CCTV), optical character recognition (OCR), printed Braille textbooks, Braille writers, Braille embossers, Braille translators, global positioning satellite (GPS) systems, and synthetic speech (Presley \& D’ Andrea, 2008).

The current study reveals that students were not solely relying on DTTs to assist learning. After using the DTTs for quite some time, low-vision students opted to revert to printed 
textbooks and CCTV, as well as notes from teachers to access the lessons. Therefore, learning for students with visual impairments depended on multiple sources including various types of assistive technology and conventional learning materials.

Students with visual impairments preferred to use printed Braille textbooks and personal readers to assist in learning. Maguvhe (2003) argued that students with visual impairments were passionate about access to printed materials, such as Braille textbooks, because they were able to get information easily. Students decided to reject DTTs because of the limitations that included lack of illustrations, tables, and charts compared to Braille textbooks for the same subjects. The researcher believes that the alternatives and limitations to DTTs hinder students from fully adopting this innovation. As a result, electronic devices such as CCTV and non-electronic optical devices such as magnifiers were more accepted, effective, and accessible than other assistive devices including DTTs, particularly to the students with low vision (Jutai, Strong, \& Russell-Minda, 2009).

\section{Alternatives to the Innovation: Adoption and Learning}

Learning among students with visual impairments occurred through multiple learning resources such as standard printed textbooks, Braille textbooks, teachers' notes, or websites. Blind students depended on Braille textbooks for most subjects. In this study, the blind students adopted DTTs for Islamic Studies because this subject does not have Braille textbooks. These students learned the subject through DTTs with additional notes from their teacher. Hence, the adoption of the innovation for Islamic Studies occurred due to the absence of other learning materials designated to the subject.

Students with low-vision have even more alternatives to the learning materials for the same subject, which include using standard printed textbooks with handheld magnifiers and 
CCTV, teachers' notes, as well as DTTs. Therefore, the adoption of DTTs by students with visual impairments, particularly students who are blind, could provide more meaningful and effective equal learning experience.

\section{Adaptation of the Innovation}

Adaptation to the innovation is an important factor influencing the adoption of an innovation (Kintsch \& DePaula, 2002; Riemer-Reiss \& Wacker, 2000; Scherer, Sax, Vanbierrvliet, Cushman, \& Scherer, 2005). Rogers (2003) called adaptation of any innovation by users in the process of adoption and implementation as re-invention. Adaptation occurs with many innovations for many adopters at the implementation stage in the innovation-decision process. In this study, two features of DTTs identified as being complicated and flexible to use were factors of adaptation. Interestingly, students modified DTTs accordingly to suit their devices, in order to access the lessons.

The Ministry of Education provided DTTs for students in the form of audio CDs with two types of files: SMIL files (Synchronized Multimedia Integration Language) and MP3 files. The files could be opened with both DAISY and with a CD player. Students without the DAISY application or CD player, copied the contents of DTTs in an MP3 format onto a thumb drive then accessed the contents using an MP3 player or with an external speaker, either of which are more affordable than other dedicated readers. The researcher assumes that students' creativity in adapting the innovation played an important role in adoption of DTTs to assist learning.

\section{Adaptation of the Innovation: Adoption and Learning}

In this study, adoption to the innovation occurred when students with visual impairments adapted the DTTs bypassing the obstacle of the unavailability of the dedicated hardware and software to access lessons. Students' creativity to adapt the DTTs could make full use of the 
innovation and enhance their learning needs. Therefore, proper adaptation to the DTTs and sharing the options possible would facilitate learning experiences for the students with visual impairments.

\section{Implications of Findings and Recommendations}

\section{Functionality of the Innovation}

The implications for practice derive from the study findings, discussion, and interpretation based on the concept of adoption and rejection of the innovation of DTTs. The first super-ordinate theme, functionality of the innovation determines the adoption of DTTs in schools for students with visual impairments. The characteristics of DTTs, which include being user-friendliness, portable, flexible, comfortable, and usable with other devices, persuaded students to adopt the innovation. The complexity of DTTs was the rejection factor to the innovation. The findings provide useful information for the Ministry to improve the future development of learning materials for students with visual impairments.

Recommendation to the Ministry of Education. Students in the current study experienced difficulty accessing the contents of DTTs because of the contents' structure and irrelevancy. It is notable that the structure of DTTs was very similar to the organization of the printed textbooks. Students reported that sections such as the acknowledgments, preface, references, as well as long irrelevant passages are not suitable to include in DTTs. Since the Ministry has the authority to determine curriculum and content of the DTTs; therefore, the Ministry should consider reducing the contents in DTTs to suit the students with visual impairments' learning needs. 


\section{Support to Use the Innovation}

The second super-ordinate theme, support to use the innovation, refers to any support that encourages and motivates students to use the innovation. Students declared they did not have strong and full support from the school administrators, teachers, and parents to adopt DTTs. The findings suggest that demonstrations on how to use the innovation and sufficient devices to access the DTTs are a crucial factor to promote adoption of DTTs among students.

Recommendation to school administrators. School administrators have a responsibility to introduce and demonstrate the innovation to teachers and students by inviting the experts from the Ministry, publishing houses, and teacher specialists in technology. This effort can be executed through in-house trainings for both teachers and students at designated times to introduce the DTTs, disseminate the usefulness of DTTs to enhance the teaching and learning process, and explore the benefits of DTTs to assist learning. Results from a survey on technology professional support among America's teachers in public schools by the National Education Association (NEA) indicated that training for teachers in the use of technology is the biggest issue in the educational setting (NEA, 2008).

Recommendation to parents and guardians. This study suggests that parents and guardians' support can motivate students with visual impairments to adopt DTTs to assist learning. Parents and guardians should cooperate with teachers and learn together with their children to understand the importance of technology in learning and daily life. They could encourage and support their children to adopt DTTs by providing laptops and affordable tools to be used with DTTs, such as external speakers and thumb drives. In addition, parents and guardians could supervise their children in using the DTTs while at home. 
Recommendation to students. This study found students reluctant to adopt the DTTs. To encourage them to have more interest in adopting the innovation, students who already adopted and are keen to learn more using the DTTs could facilitate their peers through demonstrating the correct way of using the innovation, loaning some devices, and walking through their difficult times adopting the DTTs. One possible activity, as suggested by Presley \& D'Andrea (2008), would be “Show-and-Tell." This activity encourages one student who already adopted the DTTs to explain and demonstrate the features and functions of DTTs. This type of activity would involve the all class members, including the teachers and school administrators.

\section{Knowledge of the Innovation}

The third super-ordinate theme, knowledge of the innovation, concerns students' awareness of DTTs including information on features, familiarity, purpose, and sources of information. Students reported they knew about the existence of DTTs for certain subjects from their teachers; however, they were not familiar with how to use the innovation. The current study suggested that students should be exposed to "how-to-knowledge", which is the information and hands-on skills necessary to use DTTs properly and correctly. To use DTTs efficiently, "principle-knowledge" as suggested by Rogers (2003), which concentrates on how an innovation work should be exposed to students. Students should be trained on how to use the unique features of the DTTs such as advanced bookmark in order to make full use of the innovation.

Recommendation to the stakeholders. The stakeholders, particularly the Ministry and state education departments, could concentrate on efforts to encourage school administrators, teachers, and students to adopt this innovation. These stakeholders could organize workshops 
and trainings to introduce and promote the DTTs as well as other technologies for school administrators, teachers, and students. Such introduction and promotion of DTTs can be held through on-line trainings using the Ministry portal and the state education departments' websites, as well as road shows with cooperation from publishing houses. By offering trainings, the stakeholders could stimulate school administrators, teachers, and students' interest to adopt DTTs to assist learning. Rogers (2003) claimed that it is possible to use an innovation without the principle knowledge, but rejection and discontinuance may result.

The Ministry and state education departments could also reach out to the DTTs consumers by gaining feedback after providing the innovation to them. The efforts could be extended to perform periodic assessment of DTTs' use among students with visual impairments, and to provide additional after-use services to the schools. The periodic assessment purposes would be to evaluate how students use the DTTs and what they are doing with this innovation. The other suggestion would be for the Ministry, through the teachers' training colleges, to address the importance of DTTs and technologies for students with special needs to all student teachers. This effort could encourage student teachers to apply what they have learned during their training to help the students learn better by adopting an innovation.

\section{Challenges for Effective Use of the Innovation}

The fourth super-ordinate theme, challenges for effective use of the innovation, highlights students' experiences with the unavailability of devices to access DTTs, limitations of time, and teachers' lack of trust. This study suggests that without these three challenges, students with visual impairments could adopt DTTs efficiently to assist learning.

Recommendation to school administrators and teachers. Regarding the unavailability of access to devices that can access DTTs, school administrators could provide affordable 
devices and upgraded software for students, such as external speakers, portable readers, laptops, and FS Readers to access DTTs. In addition, providing these devices for students' use during weekends at their own homes on a loan basis would lessen the time barrier. Regarding the limitations of time, school administrators could plan extended hours for access and use to the computer laboratory. To decrease teachers' lack of trust toward students and innovation, the stakeholders could provide adequate awareness and hands-on trainings and professional development of technology skills and innovation for the teachers.

\section{Alternatives to the Innovation}

The fifth super-ordinate theme, alternatives to the innovation, refers to the alternative learning resources students use to gain information pertaining to learning. Instead of using DDTs, students reported they also access the lesson using various learning materials such as printed Braille textbooks, CCTV, additional information from teachers' notes, and Internet due to the drawbacks found in DTTs.

Recommendation to the Ministry of Education. Findings from this study suggest that the Ministry, with cooperation from different divisions including the Curriculum Development Center, the Textbook Division, and the Special Education Division, could supervise the appointed DTTs developers to focus on improving the quality of DTTs. This effort includes content selection, content presentation, proof-reading, duplication, and distribution to schools. This will ensure students receive the highest quality of DTTs to foster full adoption of the innovation and improve learning. Considering students' feedback based on their experiences with the existing DTTs, the Ministry could consider producing DTTs for all subjects to improve adoption. In addition, reducing the unnecessary content and unimportant topics in DTTs, according to the students' needs, could enhance this effort. 


\section{Adaptation of the Innovation}

The sixth super-ordinate theme, adaptation of the innovation, highlights adaptation to the DTTs made by students to use the innovation more efficiently. Students reported they copied the contents of the DTTs onto a thumb drive, then used an MP3 player and portable external speakers to access content. However, using the MP3 player and portable external speaker could limit students' access to the advanced features of DTTs such as bookmarks are rendered functionless.

Recommendation to school administrators and teachers. The findings from this study suggest that the school administrators and teachers could provide appropriate devices, such as DAISY players to ensure full opportunity of using the advanced features of DTTs efficiently. Devices such as DAISY players are very expensive. The impossibility of providing the DAISY players for all students due to its high cost could be resolved by involving the Malaysian Association for the Blind, private sectors, and community members to contribute and perhaps fund these devices as part of their contributions toward enhanced education opportunities for students with visual impairments.

\section{Recommendations for Research}

These findings are an initial attempt to explore and understand the experience of students with visual impairments in using innovations, particularly DTTs. This study involved a small sample of students in a school for students with visual impairments in Malaysia. For this reason, the researcher anticipates that a replication of this study within students with visual impairments in the country is needed. The replication can be expanded to other innovations, and not be limited to DTTs, in order to form an effective framework for understanding the needs of the students with visual impairments in learning. 
Students shared their experiences in terms of characteristics of DTTs, support, knowledge and skills, benefits, as well as their challenges in using DTTs. For future studies, focus on other characteristics of innovation, parents and community support, teachers' attitudes and perceptions, and adaptations in use of the innovation is needed. The information from the study could be useful to help the stakeholders in developing better learning materials. Other than the DTTs, research may follow the audit trail of this study to explore students experiences in using other assistive technology innovations, such as electronic Braille, screen magnifiers, refreshable Braille, and touch tablets to assist learning.

\section{Assumptions Revisited}

Three assumptions the researcher presented prior to this study (in Chapter 1) were (a) DTTs are a better learning resource for students with visual impairments than printed learning materials, particularly Braille textbooks, (b) students with visual impairments make full use of DTTs to assist learning, and (c) students with visual impairments would experience the innovation in a positive way due to DTTs' features that are developed with regard to the DAISY standard. The assumptions were based on the researcher's experiences as a high school teacher and as an officer at the Textbook Division in the Ministry of Education.

The first assumption was centered on the learning resources for the students with visual impairments. The researcher assumed that DTTs were a better choice and preferred learning material for assisting learning and doing school tasks. This assumption was partially true. The study revealed that DTTs do not fit all students' needs and all subjects' needs. Specifically, students reported DTTs were not helping them learn to spell words correctly for certain subjects such as English and Malay Language. Consequently, students thought Braille textbooks were more effective choices for learning languages. 
The second assumption focused on adoption of DTTs by students with visual impairments. The researcher assumed that students make full use of DTTs as the innovation was purposely developed by the Textbook Division of the Ministry of Education to assist students accessing the lessons and encourage them to use the technology. According to Johnson (2003), talking books have been widely used in schools by students with visual impairments due to their benefits, such as develop critical listening skills, provide a bridge to important topics of discussion, and help students to pronounce difficult words. The findings partially supported this assumption. Not all the students with visual impairments who experienced the DTTs continued to use the innovation due to several factors. The factors were lack of time, insufficient devices to access DTTs, and lack of support and motivation, especially from their parents.

The last assumption centered on how the students with visual impairments experienced the DTTs' features developed based on the DAISY standard. Due to the standard, the researcher assumed that the DTTs were compatible with existing applications and hardware. DAISY Consortium (2013) strives to develop DTTs accessible for everyone so that readers can play the audio and simultaneously display the corresponding text. This assumption was partially true. Students acknowledged that the DTTs could be accessed with their personal computers and other media players such as MP3 player, DAISY players, and portable external speakers with a modification of the original files of the DTTs. However, some of the unique features of DTTs could not be used with these other players.

\section{Research Limitations}

Conditions that limit the scope of study may affect the research outcomes and are not within the researcher's control (Creswell, 2007). The limitations for this study included the characteristics of the participants, selection of participants, and the researcher's influence on the 
study. The characteristic of the participants that may influence the findings was the personal skills of using technology devices such as computers and portable readers or players to access the contents of DTTs. This characteristic was not taken into account in the participants' selection due to the unique features of DTTs that are compatible with existing applications in most computers and can be accessed with portable readers. However, it is possible that these skills may affect the students' experiences in using DTTs. Perhaps, findings related to challenges for effective use of DTTs and the functionality of the innovation could be explained by this characteristic.

This study is not intended to make a generalization to a larger population; however, the researcher made efforts to form a fairly homogeneous sample in selection of the participants as suggested by Smith, Flowers, and Larkin (2009) for an IPA study. The homogeneous sample for this study were students with the same period of exposure to DTTs would result in a similar experience. Prior to selection of participants, the researcher provided criteria for participants to the school administrators. However, the participants selected by the school administrator were not homogenous in length of time using DTTs.

Another limitation is the possible reluctance for students to discuss negative aspects of their experiences in using DTTs. Prior to each interview, the researcher introduced himself as a student and as a former officer at the Textbook Division in the Ministry of Education in order to develop students' honesty to share their experiences in using the DTTs with an officer from the Ministry. Although the researcher managed to establish rapport with the students, the researcher's status as an officer at the Textbook Division may have limited the findings of this study. The researcher's job specification in the division, which mainly involved the development of learning materials, may have affected students' willingness to reveal negative 
aspects of DTTs. Some students might think that their honest information in response to the interview questions to the officer from the Ministry will lead to a bad reputation to their school, administrators, and teachers.

\section{Researcher Reflection}

This study demonstrates the researcher's personal and professional journey in accomplishing a comprehensive study. As a novice IPA researcher, this research was not easy. The researcher experienced a complex process from the beginning of the journey and there was not an end to the discovery. Technically, to obtain permission to do research in any schools in Malaysia, the researcher had to comply with many established procedures and protocols. In addition to the procedures and protocols to gain access to the research setting, the researcher faced numerous challenges.

It was not easy to gain rich data from students. Their responses to the interview questions were short. They were busy preparing themselves for the mid-semester exam, besides their after school activities. Since the researcher collected the data in Malaysia, and the researcher is familiar with the school system and schedules, it was assumed that the researcher would choose a more appropriate time to schedule the interview sessions. From this particular

experience, the researcher learned that poor time management in conducting a dissertation study could result in anxiety and fear of not getting sufficient data to support the findings.

In this study, the school administrators selected the participants based on the criteria given by the researcher. Among the most important criterion was the familiarity with DTTs, meaning the students received and used the DTTs for at least one subject. However, the chosen students were not as familiar with DTTs as expected by the researcher. From this particular experience, the researcher learned that in conducting a study, it would be better to have an 
opportunity to enter the study setting and do initial participant observations. From these observations, the researcher could self-select participants based on purposeful sampling procedures and perhaps select a better sample.

\section{Research Conclusion}

This exploratory study interpreted reflections, opinions, and experiences of students with visual impairments in using DTTs to assist learning. To understand the phenomenon, the researcher employed IPA procedures. The findings reveal the experiences of students with visual impairments in six super-ordinate themes: functionality of the innovation, support to use the innovation, knowledge of the innovation, challenges for effective use of the innovation, alternatives to the innovation, and adaptation of the innovation. For this study, the students' decisions to adopt or to reject the DTTs were mostly dependent upon these six emergent findings. This study could be the first step in developing an understanding about the experience of students with visual impairments in using an innovation to assist learning. 


\section{REFERENCES}

Abner, G., \& Lahm, E. (2002). Implementation of assistive technology with students who are visually impaired: Teachers' readiness. Journal of Visual Impairment and Blindness, 96, 98-105.

Alper, S., \& Raharinirina, S. (2006). Assistive technology for individuals with disabilities: A review and synthesis of the literature. Journal of Special Education Technology, 21(2), 47-64.

American Printing House for the Blind. (2003). Distribution of eligible students based on the federal quota census of January 6, 2003. Retrieved from http://www.aph.org/federalquota/dist04.html

Anfara, V. A., \& Mertz, N. T. (2006). Theoretical frameworks in qualitative research. Thousand Oaks, CA: Sage Publications.

Apling, R. N., \& Jones, N. L. (2007). IDEA: Analysis of changes made by P. L. 108-466. Washington, DC: Congressional Research Service.

Assistive Technology Act of 2004. Retrieved from http://www.gpo.gov/fdsys/pkg/STATUTE118/pdf/STATUTE-118-Pg1707.pdf

Baker, P. M., \& Bellorde, C. (2004). Adoption of information and communication technologies: Key policy issues, barriers and opportunities for people with disabilities. Proceedings of the $37^{\text {th }}$ Annual Hawaii International Conference, 37, 10.

Batavia, A. I., \& Hammer, G. S. (1989). Consumer criteria for evaluating assistive devices: Implications for technology transfer. In Presperin, J. J. (Ed.), Proceedings of the $12^{\text {th }}$ annual conference of rehabilitation engineering society of North America, p. 194-195. Washington, DC: RESNA Press. 
Beard, L. A., Carpenter, L. B., \& Johnston, L. B. (2011). Assistive technology: Access for all students (2nd ed.). Upper Saddle River, NJ: Pearson Education.

Beigel, A. R. (2000). Assistive technology assessment: More than the device. Intervention in School and Clinic, 35(4), 237-243. Retrieved from http://www.ldonline.org/article/6237/

Benson, R., \& Palaskas, T. (2006). Introducing a new learning management system: An institutional case study. Australasian Journal of Educational Technology, 22(4), 548-567.

Blackhurst, A. E., \& Lahm, E., D. (2000). A brief history of special education technology. Special Education Technology Practice, 2(1), 21-35.

Bloomberg, L., D., \& Volpe, M. (2008). Completing your dissertation: A roadmap from beginning to end. Thousand Oaks, CA: Sage Publications, Inc.

Bogdan, R., \& Biklen, S. (2007). Qualitative research for education: An introduction to theories and methods. Boston, MA: Pearson Education.

Borg, J., Lindstrom, A., \& Larsson, S. (2009). Assistive technology in developing countries: National and international responsibilities to implement the convention on the rights of persons with disabilities. Lancet, 374(28), 1863-1865.

Brokop, F., \& McIntosh, S. (2009). Context situated assistive technology training and its impact on engagement, learning outcomes, and assistive technology adoption. Canadian Council on Learning: NorQuest College, 1-42.

Brooks, N. A., \& Hoyer, E. A. (1989). Consumer evaluation of assistive devices. In Proceedings of the $12^{\text {th }}$ Annual Conference of the Rehabilitation Engineering Society of North America, 358-359.

Bryant, D. P., \& Bryant, B. R. (2003). Assistive technology for people with disabilities. Boston, MA: Allyn \& Bacon. 
Buabeng-Andoh, C. (2012). Factors influencing teachers' adoption and integration of information and communication technology into teaching: A review of the literature. International Journal of Education and Development using Information and Communication Technology, 8(1), 136-155.

Burgstahler, S. (2003). The role of technology in preparing youth with disabilities for postsecondary education and employment. Journal of Special Education Technology, 18(4), 7-19.

Cahill, H., Linehan, C., McCarthy, G., Bormans, G., \& Engelen, J. (1996). Blind and partially sighted students' access to mathematics and computer technology in Ireland and Belgium. Journal of Visual Impairment \& Blindness, 90, 105-114.

Cavalier, A. R., Ferretti, R. P, \& Okolo, C. M. (1994). Technology and individual differences. Journal of Special Education Technology, 12, 175-181.

Coard, P. (2002). The impact of assistive technology on visually impaired computer users accessing the Internet. Proceedings of the $15^{\text {th }}$ Annual NACCQ, Hamilton, New Zealand, July, 202-210. Retrieved from www.naccq.ac.nz

Cook, A. M., \& Hussey, S. M. (2002). Assistive technologies: Principles and practice. St. Louis, MO: Mosby.

Cooper, H. L., \& Nichols, S. K. (2007). Technology and early Braille literacy: Using the Mountbatten ProBrailler in primary grade classrooms. Journal of Visual Impairment \& Blindness, 101, 22-33.

Copley, J., \& Ziviani, J. (2004). Barriers to the use of assistive technology for children with multiple disabilities. Occupational Therapy International, 11(4), 229-243. 
Corn, A. L., Wall, R. S., Jose, R. T., Bell, J. K., Wilcox, K. \& Perez, A. (2002). An initial study of reading and comprehension rates for students who received optical devices. Journal of Visual Impairment \& Blindness, 96, 322-334.

Creswell, J. W. (2003). Research design: Qualitative, quantitative, and mixed method approach (2nd ed.). Thousand Oaks, CA: Sage Publications.

Creswell, J. W. (2007). Qualitative inquiry and research design: Choosing among five approaches. Thousand Oaks, CA: Sage Publications.

Creswell, J. W. (2009). Research design: Qualitative, quantitative, and mixed methods approaches. Thousand Oaks, CA: SAGE Publications.

DAISY Consortium. (2013). Creating the best way to read and publish. Retrieved from http://www.daisy.org/home

DeJonge, D. M., \& Rodger, S. A. (2006). Consumer-identified barriers and strategies for optimizing technology use in the workplace. Disability and Rehabilitation: Assistive Technology, 1, 1748-3107.

Denzin, N. K., \& Lincoln, Y. (2000). Handbook of qualitative research. Thousand Oaks, CA: Sage Publications.

Derer, K. R., Polsgrove, L., Rieth, H. J. (1996). A survey of assistive technology applications in schools and recommendations for practice. [Feature]. Journal of Special Education Technology, 13, 62-80.

Dhanarajan, G. (2001). Distance education: Promise, performance and potential. The Journal of Open, Distance and e-Learning, 16(1), 61-68. 
Duarte, C., \& Carrico, L. (2007). Developing an adaptive digital talking book player with FAME. Journal of Digital Information, 8(3). Retrieved from http://journals.tdl.org/jodi/article/view/236/193

Ebersole, S., \& Vorndam, M. (2003). Adoption of computer-based instructional methodologies : A case study. International Journal on E-Learning, 2(2), 15-20.

Edyburn, D. L. (2004). Rethinking assistive technology. Special Education Practice, 5(4), 16-23.

Farnsworth, C. R., \& Luckner, J. L. (2008). The impact of assistive technology on curriculum accommodation for a Braille-reading student. RE:view, 39(4), $171-187$.

Fichten, C. S., Asuncion, J. V., Barile, M., Ferrano, V., \& Wolforth, J. (2009). Accessibility of elearning and computer and information technologies for students with visual impairments in postsecondary education. Journal of Visual Impairments \& Blindness, 103(9), 543556.

Fifield, M. G., \& Fifield, M. B. (1997). Education and training of individuals involved in delivery of assistive technology devices. Technology and Disability, 6, 77-88.

Fisher, D., \& Frey, N. (2002). Access to the core curriculum: Critical ingredients for student success. Remedial and Special Education, 22(1), 148-157.

Fraser, W. J., \& Maguvhe, M. O. (2008). Teaching life sciences to blind and visually impaired learners. Journal of Biological Education, 42(2), 84-89.

Georgia's Assistive Technology (2011). What is assistive technology? Retrieved from http://www.gatfl.org/AssistiveTechnology.aspx

Gerber, E. (2003). The benefits of and barriers to computer use for individuals who are visually impaired. Journal of Visual Impairment and Blindness, 97(9), 536-550. 
Gibbs, G. R. (2008). Analyzing qualitative data. London, UK: SAGE Publications.

Glesne, C. (2011). Becoming qualitative researchers: An introduction (4th ed.). Boston, MA: Pearson Education.

Goodman, G., Tiene, D., \& Luft, P. (2002). Adoption of assistive technology for computer access among college students with disabilities. Disability \& Rehabilitation, 24, 80-92.

Greene, S., \& Hogan, D. (2005). Researching children's experience: Methods and approaches. Thousand Oaks, CA: SAGE Publications.

Gubrium, J. F., \& Holstein, J. A. (2001). Handbook of interview research: Context and method. Thousand Oaks, CA: Sage Publications.

Hasselbring, T. S., \& Glaser, C. H. (2007). Use of computer to help students with special needs. The Future of Children, 10(2), 102-122.

Hesse-Biber, S. N., \& Leavy, P. (2011). The practice of qualitative research (2nd ed.). Thousand Oaks, CA: Sage Publications.

Holcombe, M. C. (2000). Factors influencing teacher acceptance of the Internet as a teaching tool: A study of Texas schools receiving a TIF or a TIE grant. Unpublished dissertation submitted to the Faculty of Baylor University, USA.

Howell, R. (1996). Technological aids for inclusive classrooms. Theory into Practice, 35 (1), 5865.

Huang, J., \& Russell, S. (2006). The digital divide and academic achievement. The Electronic Library, 24(2), 160-173.

Hussin, H., Mohd Nor, R., \& Suhaimi, M. A. (2008). Perceived attributes of e-commerce and the adoption decision: The case of Malaysian SMEs. Jurnal Teknologi Maklumat \& Multimedia, 5, 107-125. 
Johnson, B., \& Christensen, L. (2012). Educational research: Quantitative, qualitative, and mixed approaches (4th ed.). Thousand Oaks, CA: SAGE Publications.

Johnson, D. (2003, April). Web watch-audiobooks: Ear-resistible. Reading Online, 6(8).

Retrieved from http://www.readingonline.org/electronic/elec_index.asp?HREF=webwatch/audiobooks/in dex.html

Johnson, D. (2011). Why is assistive technology underused? Library Hi Tech News, 16(6), 1517. Retrieved from http://www.emeraldinsight.com/journals.htm?articleid=1489469\&show=html

Jutai, J. W., Strong, J. G., \& Russell-Minda, E. (2009). Effectiveness of assistive technologies for low vision rehabilitation: A systematic review. Journal of Visual Impairment \& Blindness, 103(4), 210-222.

Kapperman, G., Sticken, J., \& Heinze, T. (2002). Survey of the use of assistive technology by Illinois students who are visually impaired. Journal of Visual Impairment \& Blindness, 96(2), 106-108.

Kennedy, K. (2002). Assistive technology and the multiage classroom. Technology \& Learning, 22(8), 38-43.

Kelly, S. M. (2009). Use of assistive technology by students with visual impairments: Findings from a national survey. Journal of Visual Impairment and Blindness, 103, 470-480

Kelly, S. M., \& Smith, D. W. (2011). The impact of assistive technology on the educational performance of students with visual impairments: A synthesis of the research. Journal of Visual Impairment and Blindness, 105(2), 73-83. 
Kintsch, A., \& DePaula, R. (2002). A framework for adoption of assistive technologies. Boulder, CO: Center for Lifelong Learning Design.

Lahm, E. A., \& Nickels, B. L. (1999). What do you know? [Feature]. Teaching Exceptional Children, 32(1), 56-63.

Lee, H., \& Templeton, R. (2008). Ensuring equal access to technology: Providing assistive technology for students with disabilities. Theory Into Practice, 47(3), 212-219.

Leporini, B. (2007, August). An accessible and useable e-book as educational tool: How to get it? Paper presented at the Conference \& Workshop on Assistive Technologies for People with Vision \& Hearing Impairment (CVHI 2007), Granada, Spain. Retrieved from http://citeseerx.ist.psu.edu/viewdoc/summary?doi=10.1.1.142.8348

Lode, C. (1992). How technology assists my daughter to compete in the mainstream of life. Exceptional Parent, 22(8), 34-41.

Maguvha, M. O. (2003). Being a blind researcher in South Africa. Perspective in Education, 21(3), 117-119.

Male, M. (2003). Technology for inclusion: Meeting the special needs of all students (4th ed.). Atlanta, GA: Pearson Education Group.

Mallik, K., \& Elder, G. (1993). Consumers who choose use. In M. Binion (Ed.), Proceedings of the RESNA 93 annual conference, engineering the ADA, pp. 39-40. Washington, DC: RESNA Press.

Martins, C., Steil, A. V., \& Todesco, J. L. (2004). Factors influencing the adoption of the internet as a teaching tool at foreign language schools. Computer \& Education, 42, 353-374.

Maxwell, J. (2005). Qualitative research design: An interactive approach (2nd ed.). Thousand Oaks, CA: Sage Publications. 
McGregor, G., \& Pachuski, P. (1996). Assistive technology in schools: Are teachers ready, able, and supported? Journal of Special Education Technology, 13, 4-15.

Merbler, J. B., Azar, H., \& Ulman, J. (1999). Using assistive technology in the inclusive classroom. Preventing School Failure, 43(3), 113-118.

Merriam, S. B. (2002). Qualitative research in practice: Examples for discussion and analysis. San Francisco, CA: Jossey-Bass.

Merriam, S. B. (2009). Qualitative research: A guide to design and implementation. San Francisco, CA: John Wiley \& Sons.

Messinger-William, J., \& Marino, M. (2010). Universal design for learning and assistive technology: Leadership considerations for promoting inclusive education in today's secondary schools. NASSP Bulletin, 94, 5-16.

Ministry of Education Malaysia (2003). Educational development plan 2001-2010. Kuala Lumpur: Ministry of Education.

Ministry of Education Malaysia (2010). Braille and talking textbooks program. Retrieved from http://www.moe.gov.my/bbt/braille_en.php

Ministry of Education Malaysia (2012). Malaysia education blueprint 2012-2025: Preliminary report-executive report. Kuala Lumpur: Ministry of Education.

Moreno, R., \& Mayer, R. E. (2000). A coherence effect in multimedia learning. Journal of Educational Psychology, 97, 117-125.

National Education Association (2008). Access, adequacy, and equity in education technology: Results of a survey of America's teachers and support professionals on technology in public schools and classroom. Retrieved from www.nea.org/research/images/08gainsandgapsedtech.pdf 
Norman, K. L. (1994). Spatial visualization: A gateway to computer-based technology. Journal of Special Education, 12, 196-205.

Owens, J., Leung, P., Lamb, G., Smith, K., Shaw, J., \& Hauff, R. (1999). Assistive technology issues for students with disabilities and university staff who work with them. HERSDA Annual International Conference, Melbourne, AUS, 12-15 July. Retrieved from www.herdsa.org.au/wp-content/uploads/conference/1999/pdf/Owens.PDF

Pajo, K., \& Wallace, C. (2001). Barriers to the uptake of web-based technology by university teachers. Journal of Distance Education, 16(1), 70-84.

Pal, J., Vallauri, U., \& Tsaran, V. (2011, Feb.). Low-cost assistive technology in the developing world: A research agenda for information schools. Paper presented at the iConference, Seattle, WA, USA. Retrieved from http://dl.acm.org/citation.cfm?id=1940761.1940824

Parette, H. P. (1997). Assistive devices and services. Education and Training in Mental Retardation and Development Disabilities, 32, 267-280.

Patton, M. Q. (2002). Qualitative research and evaluative methods (3rd ed.) Thousand Oaks, CA: Sage Publications.

Peshkin, A. (2000). The nature of interpretation in qualitative research. Educational Researcher, 29(9), 5-9.

Philips, B., \& Broadnax, D. D. (1992). National survey on abandonment of technology: Final report. Washington, DC: Rehabilitation Center, National Rehabilitation Hospital.

Philips, D. (2007). Talking books: The encounter of literature and technology in the audio book. The International Journal of Research into New Media Technologies, 13(3), 293-306.

Poel, E. W. (2007). Enhancing what students can do. Educational Leadership, 64(5), 64-66. 
Presley, I., \& D’ Andrea, F. M. (2008). Assistive technology for students who are blind or visually impaired: A guide to assessment. New York, NY: AFB Press.

Reed, P., \& Lahm, E. (2005). A resource guide for teachers and administrators about assistive technology (general edition). Wisconsin Assistive Technology Initiative. Retrieved from http://www.wati.org/content/supports/free/pdf/ATResourceGuideDec08.pdf

Riemer-Reiss, M. L., \& Wacker, R. R. (1999). Assistive technology use and abandonment among college students with disabilities. International Electronic Journal for Leadership in Learning, 3(23). Retrieved from http://iejll.synergiesprairies.ca/iejll/index.php/iejll/article/view/466

Roberts, C. M. (2010). The dissertation journey: A practical and comprehensive guide to planning, writing, and defending your dissertation (2nd ed.). Thousand Oaks, CA: CORWIN.

Robinson, L. (2009). A summary of diffusion of innovations. Retrieved from http://www.enablingchange.com.au/

Roentgen, U. R., Gelderblom, G. J., Soede, M., \& Witte, P. D. (2009). The impact of electronic mobility devices for persons who are visually impaired: A systematic review of effects and effectiveness. Journal of Visual Impairment \& Blindness, 103(11), 743-753.

Rogers, E. M. (2003). Diffusion of innovation (5th ed.). New York, NY: Free Press.

Scherer, M. J. (1993). Living in the state of stuck: How technologies affect the lives of people with disabilities. Cambridge, MA: Brookline Books.

Scherer, M. J., \& Galvin, J. C. (1996). An outcome perspective of quality pathways to most appropriate technology. In J. C. Galvin \& M. J. Scherer (Eds.), Evaluating, selecting, and using appropriate assistive technology (pp. 1-26). Gaithersburg, MD: Aspen Publication. 
Scherer, M. J., Sax, C., Vanbiervliet, A., Cushman, L. A., \& Scherer, J. V. (2005). Predictors of assistive technology use: The importance of personal and psychosocial factors. Disability and Rehabilitation: An International, Multidisciplinary Journal, 27(21), 1321-1331.

Seidman, I. (1998). Interviewing as qualitative research (2nd ed.). New York, NY: Teachers College Press.

Sharp, V. (2002). Computer education for teachers. New York, NY: McGraw Hill Publishing.

Sharpe, M. E. (2011). Assistive technology attrition: Identifying why teachers abandon assistive technologies. (Doctoral dissertation). Nova Southeastern University, United States, Florida.

Silberman, R. K., \& Sacks, S. (2007). Expansion of the role of the teacher of students with visual impairments: Providing for students who also have severe/multiple disabilities. Austin, TX: Texas School for the Blind and Visually Impaired.

Silverman, D. (2010). Doing qualitative research (3rd ed.). Thousand Oaks, CA: Sage Publications.

Smith, J. A. (2004). Reflecting on the development of interpretative phenomenological analysis and its contribution to qualitative research in psychology. Qualitative Research in Psychology, 1, 39-54.

Smith, J. A., Flowers, P., \& Larkin, M. (2009). Interpretative phenomenological analysis: Theory, method, and research. Thousand Oaks, CA: SAGE Publications.

Smith, J. A. \& Osborn, M. (2008). Interpretative phenomenological analysis. In J. A. Smith (Ed.), Qualitative psychology: A practical guide to research methods (pp. 53-80). London, UK: SAGE Publications. 
Strobel, W., Fossa, J., Arthanat, S., \& Brace, J. (2006). Technology for access to text and graphics for people with visual impairments and blindness in vocational settings. Journal of Vocational Rehabilitation, 24, 87-95.

Sze, S., Murphy, J., Smith, M., \& Yu, S. (2004). An investigation of various types of assistive technology (AT) for students with disabilities. In R. Ferdig et al. (Eds.), Proceedings of Society for Information Technology \& Teacher Education International Conference (pp. 4959-4964). Chesapeake, VA: AACE.

Todis, B. J. (1996). Tools for the task? Perspectives on assistive technology in education settings. Journal of Special Education Technology, 13, 49-61.

Trucano, M. (2005). Knowledge maps: ICT in education. Retrieved from http://www.infodev.org/en/Publication.8.html

Wehmeyer, M. L. (1998). National survey of the use of assistive technology by adults with mental retardation. Mental Retardation, 36, 44-51.

Willig, C. (2008). Introducing qualitative research in psychology: Adventures in theory and method (2nd ed.). London, UK: Open University Press.

Wong, M. E., \& Cohen, L. (2011). School, family, and other influences on assistive technology use: Access and challenges for students with visual impairments in Singapore. The British Journal of Visual Impairment, 29(2), 130-144.

Yaeda, J., \& Rubin, S. E. (1992). Job roles of assistive technology service providers in the United States. International Journal of Rehabilitation Research, 15(4), 277-288. 
Yardley, L. (2008). Demonstrating validity in qualitative psychology. In J. A. Smith (Ed.), Qualitative psychology: A practical guide to research methods (pp. 235-251). London, UK: SAGE Publications.

Zhang, Y. (2000). Technology and the writing skills of students with learning disabilities. Journal of Research on Computing in Education, 32(4), 467-479. 


\title{
APPENDIX A
}

\author{
Criteria of Participant
}

\section{Participants' Criteria}

"Experiences of Students with Visual Impairments in Adoption of Digital Talking Textbooks: An Interpretative Phenomenological Analysis"

Twelve students with visual impairments should be selected based on these criteria.

1. Blind and low vision.

2. Age 13 to 17 .

3. Male and female.

4. Receive and use the digital talking textbooks (DTTs) at least in one subject. 


\section{APPENDIX B}

Interview Schedule

The guiding interview questions to explore and understand the students' experiences in using the digital talking textbooks (DTTs)

\section{A. Information about using the DTTs}

1. What do you know about the DTTs?

2. How do you get to know about the DTTs?

3. How do you access contents of the DTTs?

B. Support to use the DTTs

1. What make you decide to use the DTTs?

2. How do school administrator and teachers support you in using the DTTs?

3. How do parents and friends support you in using the DTTs?

C. Benefits/disadvantages of using the DTTs

1. What are the benefits of using the DTTs?

2. What are the disadvantages of using the DTTs?

\section{Challenges of using DTTs}

1. What are the challenges you faced in using the DTTs? 


\section{APPENDIX C}

\section{Institutional Review Board (IRB) Approval}

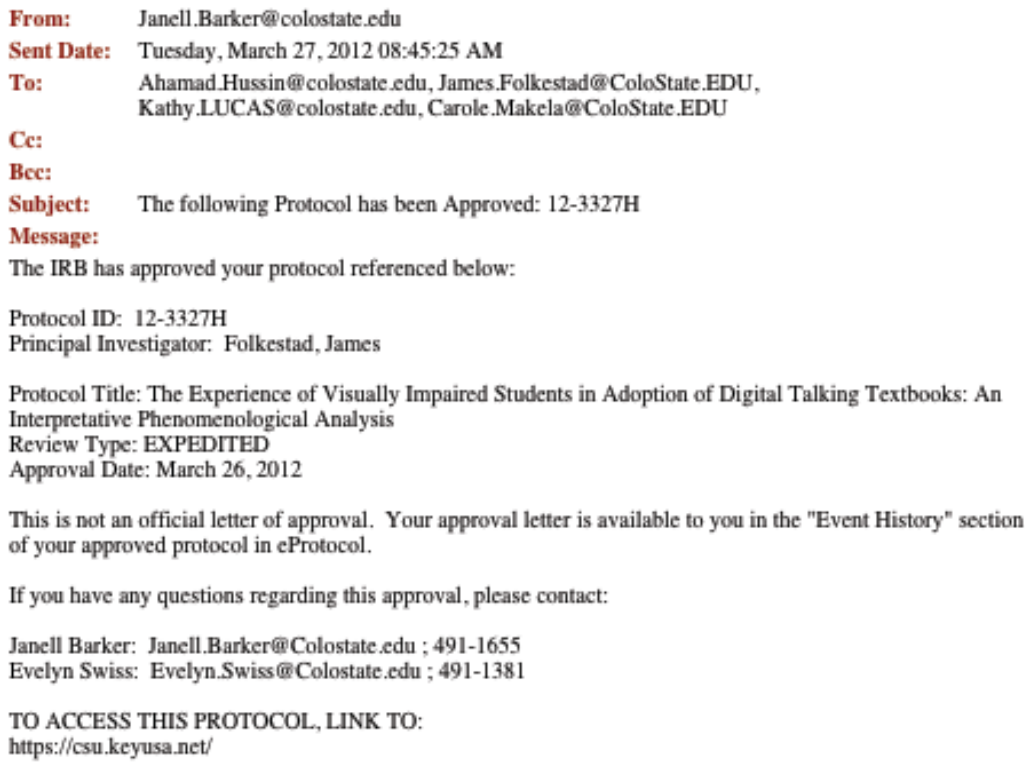




\section{APPENDIX D}

\section{Economic Planning Unit (EPU) Approval Letter}
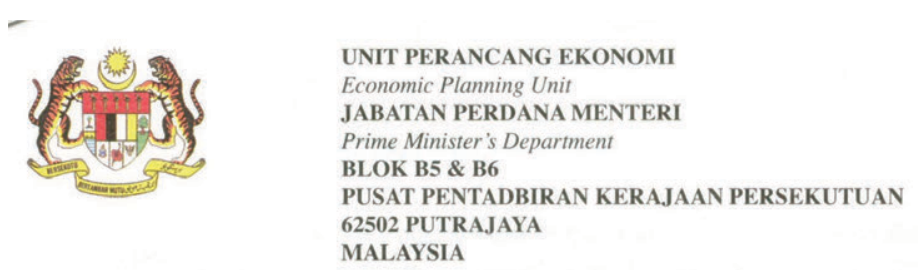

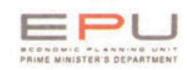

Telefon : 603-88883333

AHAMAD HUSSIN

Ruj. Tuan:

Your Ref.:

Ruj. Kami:

Our Ref.:

Tarikh:

UPE: $40 / 200 / 19 / 2876$

No. 42, Jalan Putra Permai 10/1F,

Date:

6 April 2012

Putra Heights,

47650 Subang Jaya,

Selangor.

Email: aha208_bbt@yahoo.com.my

\section{APPLICATION TO CONDUCT RESEARCH IN MALAYSIA}

With reference to your application, I am pleased to inform you that your application to conduct research in Malaysia has been approved by the Research Promotion and Co-Ordination Committee, Eccnomic Planning Unit, Prime Minister's Department. The details of the approval are as follows:

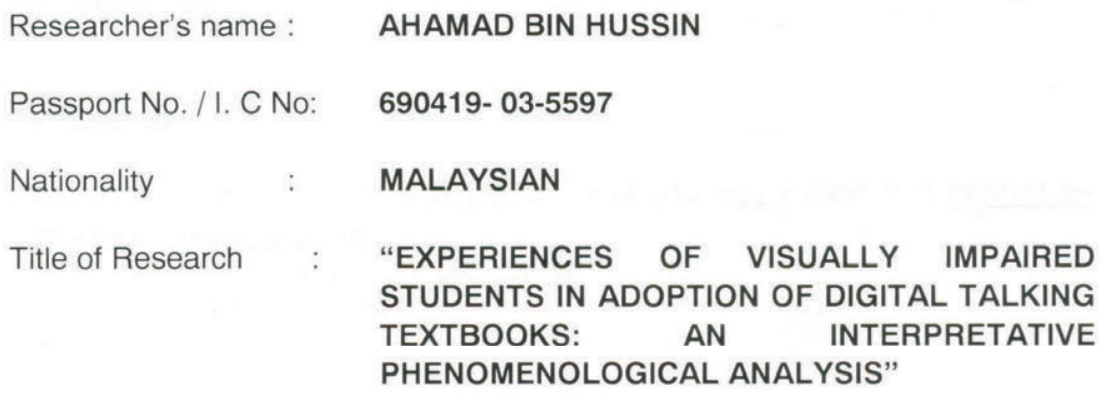

Period of Research Approved: 2 MONTHS

2. Please collect your Research Pass in person from the Economic Planning Unit, Prime Minister's Department, Parcel B, Level 4 Block B5, Federal Government Administrative Centre, 62502 Putrajaya and bring along two (2) passport size photographs. You are also required to comply with the rules and regulations stipulated from time to time by the agencies with which you have dealings in the conduct of your research. 
3. I would like to draw your attention to the undertaking signed by you that you will submit without cost to the Economic Planning Unit the following documents:

a) A brief summary of your research findings on completion of your research and before you leave Malaysia; and

b) Three (3) copies of your final dissertation/publication.

4. Lastly, please submit a copy of your preliminary and final report directly to the State Government where you carried out your research. Thank you.

Yours sincerely,

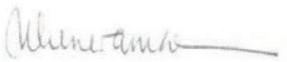

(MUNIRAH ABD. MANAN)

For Director General,

Economic Planning Unit.

E-mail: munirah@epu.gov.my

Tel: $88882809 / 2818$

Fax: 88883798

\section{ATTENTION}

This letter is only to inform you the status of your application and cannot be used as a research pass.

C.c:

Ketua Setiausaha

Kementerian Pelajaran Malaysia

Bahagian Perancangan Dan Penyelidikan Dasar Pendidikan

Aras 1-4, Blok E-8

Kompleks Kerajaan Parcel E

Pusat Pentadbiran Kerajaan Persekutuan

62604 Putrajaya

(u.p: Dr. Hj. Zabani Bin Darus)) （Ruj.Tuan:KP(BPPDP)603/01/Jld.14 (34) 


\section{APPENDIX E}

\section{The State Education Department Approval Letter}

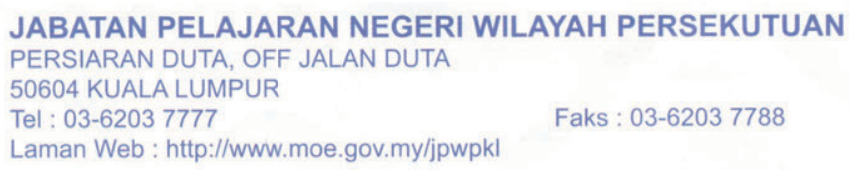

Tel : 03-6203 7777

Faks : 03-6203 7788

Laman Web : http://www.moe.gov.my/jpwpkl

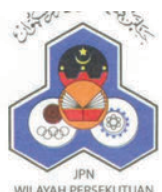

Rujukan Kami : JPNWP.900-6/1/6/Jld.II(70)

Tarikh : 16/04/2012

Ahmad Hussin

No. 42, Jalan Putra Permai 10/1F

Putra Heights, 47650 Subang Jaya Selangor

Tuan,

KEBENARAN UNTUK MENJALANKAN KAJIAN DI SEKOLAH-SEKOLAH, MAKTABMAKTAB PERGURUAN, JABATAN-JABATAN PELAJARAN DAN BAHAGIAN-BAHAGIAN DI BAWAH KEMENTERIAN PELAJARAN MALAYSIA

Dengan hormatnya saya merujuk kepada perkara di atas. Surat daripada Bahagian Perancangan Dan Penyelidikan Dasar Pendidikan, Kementerian Pelajaran Malaysia bil. KP(BPPDP)603/01/Jld.15(01) bertarikh 06/04/2012 adalah berkaitan dan saya diarah memaklumkan bahawa permohonan tuan untuk menjalankan kajian bertajuk :-

Experiences Of Visually Impaired Students In Adoption Of Digital Talking Textbooks: An Interpretative Phenomenoligical Analysis "

adalah diluluskan tertakluk kepada syarat-syarat berikut:-

a) Kelulusan ini adalah berdasarkan kepada apa yang terkandung di dalam cadangan penyelidikan yang telah diluluskan oleh Kementerian Pelajaran Malaysia.

b) Sila kemukakan surat kebenaran ini ketika berurusan dengan Pengetua/Guru Besar sekolah berkenaan.

c) Kelulusan ini untuk sekolah-sekolah di Negeri Wilayah Persekutuan sahaja

d) Tuan dikehendaki mengemukakan senaskah hasil kajian ke Jabatan ini sebaik sahaja ianya siap sepenuhnya.

e) Kebenaran ini sah sehingga 31.12 .2012

Sekian, terima kasih.

"BERKHIDMAT UNTUK NEGARA"

Saya yang menurut perintah,

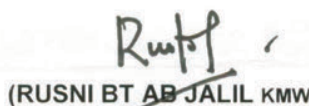

Ketua Sektor Pengurusan Sekolah

b.p Pengarah Pelajaran

Jabatan Pelajaran Negeri Wilayah Persekutuan

Sk. 1 .

Timbalan Pengarah Pejabat Pelajaran Wilayah Bangsar/Pudu

Timbalan Pengarah Pejabat Pelajaran Wilayah Putrajaya

Timbalan Pengarah Pejabat Pelajaran Wilayah Keramat

Timbalan Pengarah Pejabat Pelajaran Wilayah Sentul

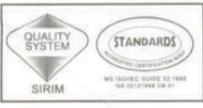




\title{
APPENDIX F
}

\section{Informed Letter to Parents/Guardian}

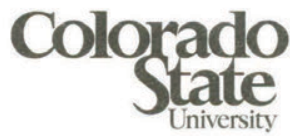 \\ School of Education \\ 1588 Campus Delivery \\ Fort Collins, Colorado 80523-1588
}

March 25, 2012

Dear Parents/Guardian,

My name is Ahamad Hussin and I am a PhD candidate at Colorado State University in the School of Education. I am conducting a research on assistive technology. The purpose of this research is to explore visually impaired students' experiences of using digital talking textbooks. The title of our research is 'Experiences of visually impaired students in adoption of digital talking textbooks: an interpretative phenomenological analysis'. The Principal Investigator is Dr. James Folkestad, School of Education and the Co-Principal Investigator is Dr. Carol Makela, School of Education.

We will be asking your child to participate in an interview, which will be tape-recorded. Participation will take approximately 45 to 60 minutes. Your child's participation in this research is voluntary. If your child would rather not to participate in this research, he/she can opt out without penalty.

All recording will be destroyed after the research. While there are no direct benefits to your child, we hope to gain more knowledge on students' experiences of using digital talking textbooks that we can report to the Ministry of Education to consider for developing of learning materials in the future. Information reported to the ministry and other agencies will not identify any student; only aggregated information will be reported.

There are no known risks to taking part in the study. It is not possible to identify all potential risks in research procedures, but the researcher(s) have taken reasonable safeguards to minimize any known and potential, but unknown, risks.

If you have any questions, please contact

1. Dr. James Folkestad at 970-491-7823 or james.folkestad@ colostate.edu

2. Dr. Carol Makela at 970-491-5141 or makela@cahs.colostate.edu

3. Ahamad Hussin at 03-51925969 or ahamad@lamar.colostate.edu 
If you have any questions about your rights as a volunteer in this research, contact Janell Barker, Human Research Administrator, CSU at 970-491-1655 or the Ministry of Education, Malaysia at 03-88846000.

Sincerely,
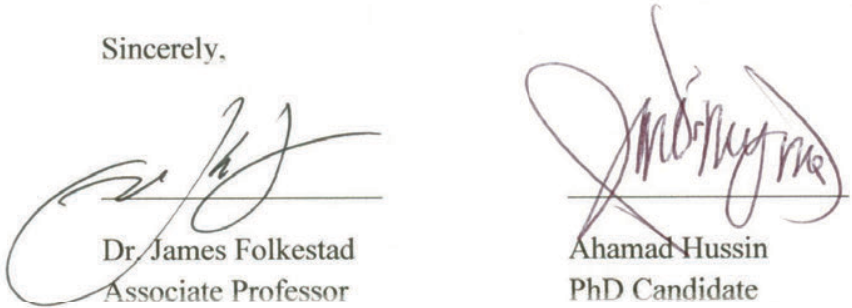

\section{Acknowledgment}

I am interested and would allow my child to participate in this research.

Sincerely,

(Parent's signature) 


\section{APPENDIX G}

\section{Informed Letter to Student}

\section{Colorado}

School of Education

1588 Campus Delivery

Fort Collins, Colorado 80523-1588

March 25, 2012

Dear Student,

My name is Ahamad Hussin and I am a PhD candidate at Colorado State University in the School of Education. I am conducting a research on assistive technology. The purpose of this research is to explore visually impaired students' experiences of using digital talking textbooks. The title of our research is 'Experiences of visually impaired students in adoption of digital talking textbooks: an interpretative phenomenological analysis'. The Principal Investigator is Dr. James Folkestad, School of Education and the Co-Principal Investigator is Dr. Carol Makela, School of Education.

We would like you to participate in an interview, which will be tape-recorded. Participation will take approximately 45 to 60 minutes. Your participation in this research is voluntary. If you would rather not to participate in this research, you can opt out without penalty.

All recording will be destroyed after the study. While there are no direct benefits to you, we hope to gain more knowledge on students' experiences of using digital talking textbooks that we can report to the Ministry of Education to consider for developing of learning materials in the future. Information reported to the ministry or other agencies will not identify you as a student; only aggregated information will be reported.

There are no known risks to taking part in the study. It is not possible to identify all potential risks in research procedures, but the researcher(s) have taken reasonable safeguards to minimize any known and potential, but unknown, risks.

If you have any questions, please contact

1. Dr. James Folkestad at 970-491-7823 or james.folkestad@colostate.edu

2. Dr. Carol Makela at 970-491-5141 or makela@cahs.colostate.edu

3. Ahamad Hussin at 970-492-9268 or ahamad@lamar.colostate.edu 
If you have any questions about your rights as a volunteer in this research, contact Janell Barker, Human Research Administrator, CSU at $970-491-1655$ or the Ministry of Education, Malaysia at $03-88846000$

Sincerely,

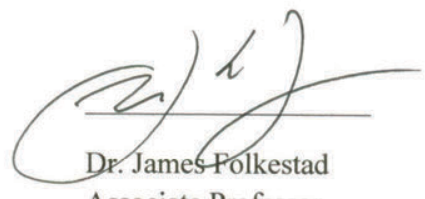

Associate Professor

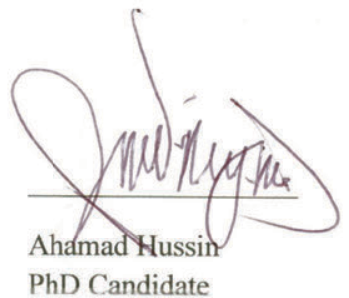

$\mathrm{PhD}$ Candidate

\section{Acknowledgment}

I am informed and interested to participate in this research.

Sincerely,

(Student's signature) 


\section{APPENDIX H}

Demographics Information

THE PARTICIPANT DEMOGRAPHICS INFORMATION FORM

Participant\#:

For each item, please check the response alternative that fits student.

1. Age

: _ـ 13 years old

: _ـ 14 years old

: _ 15 years old

: _ـ 16 years old

: _ـ 17 years old

2. Gender

: _ـ Male

: Female

3. Type of Visual

: Blind Impairments

: Low Vision

4. Computer Skill

$:{ }^{\text {Basic }}$
$:$ Intermediate
Advance




\section{APPENDIX I \\ Exploratory Comments (Extract)}

941: $\mathrm{N}$ : They said it is a great way of leaming. We could listen to the textbooks, gain the knowledge, and discuss the contents together. ${ }^{19}$

442: P: To what extent do the digital talking textbooks help you in learning?

943. $\mathrm{N}$ : It really does help. My tasks have been becoming very easy to do chapter revisions ${ }^{20}$.

Furthermore, I do have copies of the digital textbooks' contents in mp3 files. We can save

everything in a pen drive, and we could listen to it anywhere at our own convenience. ${ }^{21}$

944: P: What else do you think the benefits of the digital talking textbooks?

445. N: I think the benefits would be it is very user-friendly and a portable assistive learning

tool $^{22}$. Secondly, we do not have to wait for the teachers to introduce the subject matters:

however, we could go ahead and listen, and we certainly could comprehend the contents. ${ }^{23}$

When we are in the class discussion sessions, we could easily relate to the topics discussed. The

digital talking textbooks really help us to comprehend and be prepared for the group

discussions. ${ }^{24}$

446. P: You certainly quite familiar with the digital talking textbooks by now. What are some of its drawbacks that you could think of?

447. N: I think the voices from the digital talking textbooks were really 'slow'.

548: P: What do you mean by 'slow'?

49: N: The words or sentences pronounced were a bit 'slow' ... I mean, the reading speed of the

text is slow. ${ }^{25}$

550: P: I got you. What are the other challenges or limitations for you while using the digital

talking textbooks? 
${ }^{9}$ Could be used everywhere $\{$ User-friendly\}

${ }^{10}$ Have support from classmates \{Peers' support\}

${ }^{11}$ Encouraging support group \{Usefulness of the innovation\}

${ }^{12}$ Have support from subjects' teachers \{Teachers' support\}

13 "Memorize the facts" \{Usefulness of the innovation\}

${ }^{14}$ Got support from parents \{Parents' support\}

15 "User-friendly" learning tool \{User-friendly\}

${ }^{16}$ Got support from school \{Teachers' support\}

17 "explore by myself" \{Self motivation\}

18 "easy to be used" \{User-friendly\}

19 "Great way of learning" \{Usefulness of the innovation\}

${ }^{20}$ Helping students in chapter revsions \{Usefuness of the innovation\}

${ }^{21}$ Modification to the innovation \{Adaptation\}

22 "portable assistive learning tool" \{User-friendly\}

${ }^{23}$ Encouraging self-learning (Usefulness of the innovation)

24 "Group disscussion" \{Usefulness of the innovation\}

${ }^{25}$ Dislike the reading speed \{Limitation of the innovation\}

${ }^{26}$ Portable learning tool \{User-friendly\}

${ }^{27}$ Have an option to access the lesson (Alternative to the innovation\}

28 "Comfortable with the innovation" \{Convenient\} 


\section{APPENDIX J}

\section{Super-ordinate Themes Table (Extract)}

Super-ordinate Themes Table (Extract)

\begin{tabular}{|c|c|c|}
\hline Super-ordinate Themes & Coded Text & Source \\
\hline Adaptation of the Innovation & $\begin{array}{l}\text { I do have copies of the digital } \\
\text { textbooks' contents in mp3 files. } \\
\text { We can save everything in a pen } \\
\text { drive, and we could listen to it } \\
\text { anywhere at our own convenience } \\
(\uparrow 43) \text {. }\end{array}$ & Naim \\
\hline $\begin{array}{l}\text { Challenges for Effective Use of } \\
\text { the Innovation }\end{array}$ & $\begin{array}{l}\text { The computer laboratory at } \\
\text { school is operated within a very } \\
\text { limited time schedule }(\uparrow 43)\end{array}$ & Zaiful \\
\hline \multirow[t]{3}{*}{$\begin{array}{l}\text { Encouragement and Motivation } \\
\text { to Use the Innovation }\end{array}$} & $\begin{array}{l}\text { They really encourage us to use } \\
\text { the digital talking textbooks } \\
\text { because it is very practical ( } ₫ 33 \text { ). }\end{array}$ & Naim \\
\hline & $\begin{array}{l}\text { The teachers granted the } \\
\text { permission to bring my computer } \\
\text { while in the classroom }(\uparrow 25)\end{array}$ & Zaiful \\
\hline & $\begin{array}{l}\text { They [parents] are absolutely } \\
\text { okay with the digital talking } \\
\text { textbooks, mainly because it } \\
\text { serves its purpose well. I use it } \\
\text { sometimes at home...and they } \\
\text { [parents] also encourage me to } \\
\text { use it ( } ₫ 35) \text {. }\end{array}$ & Naim \\
\hline Functionality of the Innovation & $\begin{array}{l}\text { I use the DAISY player to listen } \\
\text { to the books...Sometimes I use } \\
\text { laptop }(\boldsymbol{\varsigma} 30) \text {. }\end{array}$ & Hong \\
\hline
\end{tabular}




\section{APPENDIX K}

\section{Audit Statement}

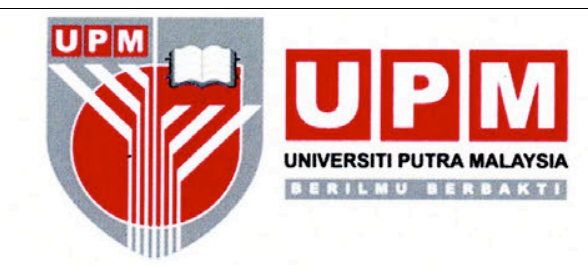

Date : January 25, 2013

To Whom It May Concern,

This letter is to certify that an independent audit was conducted for this study entitled Experiences of Students with Visual Impairments in Adoption of Digital Talking Textbooks: An Interpretative Phenomenological Analysis by Ahamad Hussin, School of Education, Colorado State University, USA.

For this study, I reviewed and audited the interview transcripts, themes development process, themes tables, and final report. I followed the Interpretative Phenomenological Analysis (IPA) procedures based on the research question. I also worked closely with the researcher throughout each phase and reviewed the content of this study. In addition, I met once with the researcher's advisor to conclude the overall study. Throughout the reviewing and auditing process, questions raised to the researcher were clarified and crystallized, which helped the researcher refine his work on each phase.

It is important to note that the purpose of an independent audit for a qualitative research is not to present consensus about a study or to represent the truth. It is intended to inform how systematically and transparently the study has been conducted. Should there be any questions or concerns, please do not hesitate to contact me.

Thank you.

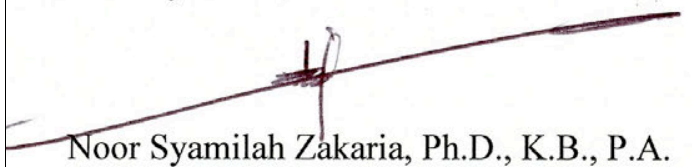

Department of Counselor Education and Counseling Psychology

Faculty of Educational Studies

Universiti Putra Malaysia

43400 Serdang, Selangor Darul Ehsan, Malaysia.

E-mail: syamilah@upm.edu.my

Post-Doctoral Scholar

Department of Professional Studies-Counselor Education

College of Education

University of Wyoming

82070 Laramie, Wyoming, USA.

E-mail:nzakari1@uwyo.edu 